\title{
Plasma Membrane Transporters of Serotonin, Dopamine, and Norepinephrine Mediate Serotonin Accumulation in Atypical Locations in the Developing Brain of Monoamine Oxidase A Knock-Outs
}

\author{
Olivier Cases, ${ }^{1}$ Cecile Lebrand, ${ }^{2}$ Bruno Giros, ${ }^{3}$ Tania Vitalis, ${ }^{1}$ Edward De Maeyer, ${ }^{4}$ Marc G. Caron, ${ }^{5}$ \\ David J. Price, ${ }^{1}$ Patricia Gaspar, ${ }^{2}$ and Isabelle Seif ${ }^{4}$ \\ 1Department of Physiology, Medical School, Teviot Place, Edinburgh EH8 9AG, Scotland, 2Unité 106 et 3Unité 288, \\ Institut National de la Santé et de la Recherche Médicale, Hôpital de la Pitié-Salpêtrière, 75651 Paris Cedex 13, France, \\ ${ }^{4}$ Centre National de la Recherche Scientifique Unité Mixte de Recherche 146, Institut Curie, Bâtiment 110, 91405 Orsay \\ Cedex, France, and ${ }^{5}$ Department of Cellular Biology and Medicine, Duke University Center, Durham, North Carolina \\ 27710
}

Genetic loss or pharmacological inhibition of monoamine oxidase $A(M A O A)$ in mice leads to a large increase in whole-brain levels of serotonin (5-HT). Excess $5-\mathrm{HT}$ in mouse neonates prevents the normal barrel-like clustering of thalamic axons in the somatosensory cortex. Projection fields of other neuron populations may develop abnormally. In the present study, we have analyzed the localization of 5-HT immunolabeling in the developing brain of MAOA knock-out mice. We show numerous atypical locations of 5-HT during embryonic and postnatal development. Catecholaminergic cells of the substantia nigra, ventral tegmental area, hypothalamus, and locus ceruleus display transient 5-HT immunoreactivity. Pharmacological treatments inhibiting specific monoamine plasma membrane transporters and genetic crosses with mice lacking the dopamine plasma membrane transporter show that the accumulation of $5-\mathrm{HT}$ in these catecholaminergic cells is attributable to 5-HT uptake via the dopamine or the norepinephrine plasma membrane transporter. In the telencephalon, transient 5-HT immunolabeling is observed in neurons in the CA1 and CA3 fields of the hippocampus, the central amygdala, the indusium griseum, and the deep layers of the anterior cingulate and retrosplenial cortices. In the diencephalon, primary sensory nuclei, as well as the mediodorsal, centrolateral, oval paracentral, submedial, posterior, and lateral posterior thalamic nuclei, are transiently 5-HT immunolabeled. The cortical projections of these thalamic nuclei are also labeled. In the brainstem, neurons in the lateral superior olivary nucleus and the anteroventral cochlear nucleus are transiently 5-HT immunolabeled. None of these structures appear to express the monoamine biosynthetic enzyme L-aromatic amino acid decarboxylase. The administration of monoamine plasma membrane transporter inhibitors indicates that the 5-HT immunolabeling in these structures is attributable to an uptake of 5-HT by the 5-HT plasma membrane transporter. This points to neuron populations that form highly precise projection maps that could be affected by 5 -HT during specific developmental stages.

Key words: monoamine oxidase; serotonin; serotonin transporter; dopamine transporter; norepinephrine transporter; brain development
Serotonin (5-HT) has been shown to modulate brain developmental events such as neural crest migration (Moiseiwitsch and Lauder, 1995), cortical neuronal differentiation (Ladvas et al., 1997), and the refinement of thalamocortical connections ( $\mathrm{Gu}$ and Singer, 1995; Cases et al., 1996). We recently demonstrated that mice that cannot normally degrade 5-HT because of a genetic lack of monoamine oxidase A (MAOA) have greatly enhanced levels of 5-HT in the brain during early postnatal life (Cases et al., 1995) and display an abnormal development of the primary somatosensory cortex in which the barrel-like clustering of neurons and thalamic axons fails to occur (Cases et al., 1996). This can be

\footnotetext{
Received March 23, 1998; revised June 8, 1998; accepted June 10, 1998.

This work was funded by the European Commission (BMH4 CT97-2412 and Biotech Bio4CT-965048), the University of Edinburgh, the Institut National de la Santé et de la Recherche Médicale, the Centre National de la Recherche Scientifique, and the Curie Institute. We thank Pascal Ezan and Vincent Martinez for technical help, Denis Lecren for photographic assistance, and Diana Haranger for animal care.

Correspondence should be addressed to Olivier Cases, Department of Physiology, Medical School, Teviot Place, Edinburgh, EH8 9AG, Scotland.

Copyright (C) 1998 Society for Neuroscience $0270-6474 / 98 / 186914-14 \$ 05.00 / 0$
}

prevented by reducing 5-HT levels in MAOA knock-outs during an early postnatal developmental period (Cases et al., 1996). Similarly, an abnormal development of the barrel field can be reproduced in wild-type mice by inhibiting MAOA pharmacologically during the same critical period (Cases et al., 1996; Vitalis et al., 1998). Interestingly, during this same critical period, somatosensory thalamic neurons that instruct the formation of the cortical barrels transiently express serotonergic markers such as the 5- $\mathrm{HT}_{1 \mathrm{~B}}$ receptor (Bennett-Clarke et al., 1993), the 5-HT plasma membrane transporter SERT, and the vesicular monoamine transporter VMAT2 (Lebrand et al., 1996). The presence of these transporters allows an active internalization of 5-HT from the extracellular space into presynaptic terminals and its storage in vesicles (Lebrand et al., 1996). Thus, although somatosensory thalamic neurons do not produce 5-HT, they appear to transiently contain the amine. This phenomenon is amplified when the degradation of 5-HT is prevented by MAOA inhibitors (D'Amato et al., 1987; Lebrand et al., 1996; Vitalis et al., 1998) and is best observed 
in MAOA knock-outs. Indeed, this phenomenon was first strongly suggested by observations in MAOA knock-outs that showed unambiguously the transient presence of 5-HT in thalamic neurons (Lebrand et al., 1996).

As first reported here in detail, MAOA knock-outs have been a most powerful tool to identify neuronal populations in which 5-HT is internalized during development. We have determined whether each suspected case of 5-HT internalization is attributable to an heterologous expression of SERT or to a cross-binding to other monoamine plasma membrane transporters. Our previous immunocytochemical localization of 5-HT in MAOA knockouts (Cases et al., 1995) in 8-d-old pups had suggested the possibility of an internalization by the catecholaminergic transporters, because 5-HT was observed in the brainstem catecholaminergic neurons (Cases et al., 1995). Monoaminergic plasma membrane transporters specific for 5-HT, dopamine, or norepinephrine belong to the family of $\mathrm{Na}^{+} / \mathrm{Cl}^{-}$-dependent transporters and display a significant degree of amino acid identity (Amara and Kuhar, 1993; Giros and Caron, 1993; Nelson and Lill, 1994), but no clear evidence of significant cross-reactivity of catecholaminergic transporters with 5-HT in vivo has ever been reported.

We report here transient and abnormal 5-HT immunolabeling in a number of neuronal structures in the cerebral cortex, the hippocampal formation, the amygdala, the thalamus, the hypothalamus, and the brainstem. In most of the nonaminergic structures, specific inhibitors of SERT abolished the 5-HT immunolabeling. Indeed, these locations coincide with the transient expression pattern of SERT (Hansson et al., 1998; Lebrand et al., 1998). Interestingly, 5-HT immunolabeling of each of these structures has a developmental timing, suggesting that they may be sensitive to the effects of 5-HT during these specific periods. Furthermore, we analyzed in greater detail the abnormal localization of 5-HT in catecholaminergic structures. Using pharmacological experiments and genetic crosses with mice lacking the dopamine plasma membrane transporter (Giros et al., 1996), we determined that 5-HT uptake in catecholaminergic neurons can be entirely accounted for by the dopamine plasma membrane transporter (DAT) or the norepinephrine plasma membrane transporter (NET).

\section{MATERIALS AND METHODS}

Animals. MAOA knock-outs and their $\mathrm{C} 3 \mathrm{H} / \mathrm{He}$ controls were as described in Cases et al. (1995). MAOA-DAT double knock-outs and their diverse controls were obtained in the F2 progeny from crosses between the MAOA knock-outs and DAT knock-outs (Giros et al., 1996) having a mixed genetic background (129/Sv, C57BL/6, and DBA/2). MAOA knock-outs were analyzed at embryonic day 12 (E12), E15, E16, E17, E18, E19 (the day of the vaginal plug was counted as E1), postnatal day 0 (P0), P4, P7, P10, P15, P21, P28, P60, and 2-6 months (the day of birth was counted as P0). MAOA-DAT double knock-outs were analyzed at E16, E19, P0, P4, and P7. All mice lacking DAT were given hydrated food pellets on the cage floor, and it was not necessary to transfer offspring to foster mothers. Animal procedures were conducted in strict compliance with approved institutional protocols and in accordance with the provisions for animal care and use described in the Scientific Procedures on Living Animals ACT 1986.

Immunocytochemistry. 5-HT immunocytochemistry was performed using a rat anti-5-HT monoclonal antibody (1:50; Harlan, Sussex, UK). The specificity of this antibody has been demonstrated previously (Consolazione et al., 1981; Lebrand et al., 1996). Rabbit polyclonal antibodies were used for detection of tyrosine hydroxylase (TH) (1:5000; gift from A. Vigny) and L-aromatic amino acid decarboxylase (AADC) (1:1000; Protos Biotech) (Joh and Ross, 1983).

Embryonic and postnatal mice were transcardially perfused with saline, followed by $4 \%$ paraformaldehyde in $0.1 \mathrm{M}$ phosphate buffer, $\mathrm{pH}$ 7.2.
Whole embryos or brains were post-fixed $1-5 \mathrm{~d}$ in the same fixative and cryoprotected in $30 \%$ sucrose in $0.1 \mathrm{M}$ phosphate buffer. Serial coronal sections $(40 \mu \mathrm{m})$ were cut on a freezing microtome and immediately processed for 5-HT, TH, or AADC immunocytochemistry as described previously (Cases et al., 1996). In brief, sections were washed in $0.1 \mathrm{M}$ phosphate buffer and incubated $1 \mathrm{hr}$ in PBS + (0.1 M PBS with $0.2 \%$ gelatin and $0.25 \%$ Triton X-100). Sections were incubated with the primary antibodies for $24 \mathrm{hr}$ at $4^{\circ} \mathrm{C}$. Then, sections were washed in PBS+ and incubated with secondary antibodies (biotinylated goat anti-rat for 5-HT immunocytochemistry or biotinylated swine anti-rabbit for AADC immunocytochemistry) (1:200; Dako, High Wycombe, UK) for $2 \mathrm{hr}$ at room temperature. Sections were washed in PBS + and incubated with a streptavidin-biotin-peroxidase complex (1:200; Amersham, Arlington Heights, IL) for $2 \mathrm{hr}$ at room temperature. Sections were then reacted with a solution containing $0.02 \%$ diaminobenzidine, $0.6 \%$ nickel ammonium sulfate (Carlo Erba), and $0.003 \% \mathrm{H}_{2} \mathrm{O}_{2}$ in $0.05 \mathrm{M}$ Tris buffer, $\mathrm{pH}$ 7.6. Sections were mounted on 3-aminopropyltriethoxysilane-coated slides, dehydrated, and coverslipped in DePeX.

Some coronal sections were counterstained with a solution containing $1 \%$ methyl green in $70 \%$ ethanol.

Double 5-HT and TH immunofluorescence. Frozen cryostat sections (20 $\mu \mathrm{m})$ were incubated in the 5-HT antiserum (clone YC5/45) $(1: 1000$ of a $5 \times$ concentrated batch) mixed with the TH antiserum (1:5000) overnight at room temperature. After rinsing in $\mathrm{PBS}+$, sections were incubated with rhodamine-conjugated anti-rat (1:100; Amersham) and fluoresceinconjugated anti-rabbit (1:70; Silenus, Hawthorne, Australia) for $2 \mathrm{hr}$ at room temperature. Sections were rinsed in PBS for $30 \mathrm{~min}$ and mounted with glycerol-PBS (3:1).

In situ hybridization. To prepare the SERT cRNA probes, a cDNA fragment corresponding to nucleotides 1510-2009 of the transcript (Blakely et al., 1991) was amplified by PCR and subcloned into pBluescript SKII (Stratagene, La Jolla, CA). The plasmid was linearized with BamHI (Boehringer Mannheim, Indianapolis, IN) for antisense RNA synthesis by T7 polymerase (Pharmacia, Piscataway, NJ) and with EcoRI (Boehringer Mannheim) for sense RNA synthesis by T3 polymerase (Boehringer Mannheim).

The in vitro transcription was performed using a kit from Promega (Madison, WI), and probes were labeled with ${ }^{35} \mathrm{~S}-\mathrm{UTP}(>1000 \mathrm{Ci} / \mathrm{mmol}$; Amersham) as described by Fontaine and Changeux (1989). In situ hybridization for cRNA probes was performed using fresh frozen brain sections (15 $\mu \mathrm{m}$ thick). Tissue sections were post-fixed for $15 \mathrm{~min}$ in $4 \%$ paraformaldehyde, washed in PBS, acetylated, washed in PBS, dehydrated, and air-dried. Sections were covered with hybridization buffer containing $5 \times 10^{4} \mathrm{cpm} / \mu \mathrm{l}{ }^{35} \mathrm{~S}$-SERT $(12.5 \mu \mathrm{l} / \mathrm{section})$ and then incubated overnight in a humid chamber at $48^{\circ} \mathrm{C}$. Washes were then performed as described previously (Fontaine and Changeux, 1989). Autoradiograms were obtained by apposing the sections to $\beta$-max hyperfilms (Amersham) for $4 \mathrm{~d}$. For histological analyses, the slides were dipped in photographic emulsion (NTB2; Eastman Kodak, Rochester, NY) and exposed for $\sim 10 \mathrm{~d}$. After development of the emulsion, the sections were counterstained with cresyl violet.

Pharmacological treatments. Drugs and vehicle (0.9\% saline) were administered subcutaneously in P6-P7 pups. Four main administration protocols were used: (1) two injections at a $14 \mathrm{hr}$ interval; (2) three injections at $4 \mathrm{hr}$ intervals; (3) three injections at $10 \mathrm{hr}$ intervals; and (4) seven injections at $4 \mathrm{hr}$ intervals. All animals were killed 4-6 hr after the last injection. The drugs used were fluoxetine (10 or $30 \mathrm{mg} / \mathrm{kg}$; Eli Lilly), paroxetine $(50 \mathrm{mg} / \mathrm{kg}$; Beecham), GBR12783 (10 or $30 \mathrm{mg} / \mathrm{kg}$; gift of Dr. J. Constentin, Unité de Neuropsychopharmacology, Saint Etiénne de Rouvray, France), nisoxetine (10 or $30 \mathrm{mg} / \mathrm{kg}$; Research Biochemicals, Natick, MA), or NO-711 (50 mg/kg; Research Biochemicals). Fluoxetine was also administered intraperitoneally to pregnant dams $(30 \mathrm{mg} / \mathrm{kg})$ during the E18-E19 developmental period. Embryos were removed by cesarean section and perfused $4 \mathrm{hr}$ after the last injection.

\section{RESULTS}

\section{Unusual localization of 5-HT-containing neurons in MAOA knock-outs}

The immunocytochemical localization of 5-HT was performed in parallel in MAOA-deficient and normal mice during embryonic and postnatal development. In the following, we will focus our description on the localization of 5-HT-labeled structures in MAOA knock-outs that was not observed in normal mice. The 


\begin{tabular}{|c|c|c|c|c|c|c|c|c|}
\hline & $\begin{array}{l}\text { E15 } \\
n=4\end{array}$ & $\begin{array}{l}\text { E18 } \\
n=5\end{array}$ & $\begin{array}{l}\text { P0 } \\
n=6\end{array}$ & $\begin{array}{l}\text { P7 } \\
n=6\end{array}$ & $\begin{array}{l}\mathrm{P} 10 \\
n=2\end{array}$ & $\begin{array}{l}\text { P15 } \\
n=1\end{array}$ & $\begin{array}{l}\mathrm{P} 21 \\
n=3\end{array}$ & $\begin{array}{l}\text { Adult } \\
n=2\end{array}$ \\
\hline \multicolumn{9}{|l|}{ Telencephalon } \\
\hline Cingulate cortex $(\mathrm{Cg} 1+\mathrm{Cg} 2)$ & - & +++2 & ++2 & ++2 & ++2 & - & - & - \\
\hline Retrosplenial cortex & - & +++2 & +2 & - & - & - & - & - \\
\hline Indusium griseum & - & +++3 & +2 & - & - & - & - & - \\
\hline Hippocampus (CA1 + CA3) & - & +++3 & +2 & - & - & - & - & - \\
\hline Amygdala & ++1 & +++1 & +++1 & - & - & - & - & - \\
\hline \multicolumn{9}{|l|}{ Diencephalon } \\
\hline \multicolumn{9}{|l|}{ Hypothalamic nuclei } \\
\hline Periventricular preoptic & ++2 & ++2 & - & - & - & - & - & - \\
\hline Suprachiasmatic preoptic & ++2 & ++3 & - & - & - & - & - & - \\
\hline Suprachiasmatic & - & - & - & +1 & ++2 & ++2 & +2 & - \\
\hline Paraventricular & ++3 & - & - & - & - & - & - & - \\
\hline Arcuate & ++2 & ++2 & - & ++1 & ++1 & ++1 & - & - \\
\hline \multicolumn{9}{|l|}{ Thalamic nuclei } \\
\hline Mediodorsal & - & +2 & +2 & +++3 & ++3 & - & - & - \\
\hline Centrolateral & - & - & ++2 & +++2 & ++2 & - & - & - \\
\hline Oval paracentral & - & - & +3 & +++3 & ++3 & - & - & - \\
\hline Submedial & - & ++3 & ++3 & ++3 & +3 & - & - & - \\
\hline Ventroposteromedial (VPM) & - & +++3 & +++3 & +++3 & ++3 & - & - & - \\
\hline Ventroposterolateral (VPL) & ++2 & +++3 & +++3 & +++3 & ++3 & +2 & - & - \\
\hline VPM, parvicellular & +2 & ++3 & +++3 & ++3 & - & - & - & - \\
\hline VPL, parvicellular & +2 & ++3 & +++3 & ++3 & - & - & - & - \\
\hline Posterior & - & - & +2 & ++2 & +2 & - & - & - \\
\hline Lateral posterior & - & - & - & +++2 & ++2 & - & - & - \\
\hline Dorsal lateral geniculate & ++3 & +++3 & +++3 & +++3 & ++3 & +3 & - & - \\
\hline Medial geniculate ventral & - & +++3 & +++3 & +++3 & ++3 & - & - & - \\
\hline Medial geniculate medial & - & - & ++2 & +++3 & ++3 & - & - & - \\
\hline Medial geniculate dorsal & - & - & ++2 & +++3 & ++3 & - & - & - \\
\hline \multicolumn{9}{|l|}{ Brainstem } \\
\hline Substantia nigra (A9) & ++3 & +++3 & +++3 & +++3 & +++3 & ++3 & ++3 & - \\
\hline Ventral tegmental area (A10) & ++3 & +++3 & +++3 & +++3 & +++3 & +3 & +3 & - \\
\hline Retrorubral field (A8) & ++3 & +++3 & +++3 & +++3 & +++3 & +3 & +3 & - \\
\hline Lateral superior olivary n. & - & +2 & ++3 & ++3 & - & - & - & - \\
\hline Anteroventral cochlear n. & - & ++2 & - & - & - & - & - & - \\
\hline Subcoeruleus (A5) & ++3 & ++3 & +++3 & +++3 & ++3 & ++3 & - & - \\
\hline Locus coeruleus (A6/7) & +++3 & +++3 & +++3 & +++3 & +++3 & +++3 & ++3 & - \\
\hline
\end{tabular}

Staining intensity of neurons at prenatal and postnatal ages according to locations in the brain.

Cell staining: - none; + light staining; ++ moderate staining; +++ heavy staining.

Cell number: 1 , few scattered cells; 2 , moderate number of cells (10 to 50\%); 3, majority of cells.

general distribution of these labeled structures is given in Tables 1 and 2. The nomenclature is taken from Schambra et al. (1992) and Paxinos et al. (1991) for embryonic stages and from Franklin and Paxinos (1994) for postnatal stages. For the normal distribution of 5-HT, see the descriptions of Steinbusch (1981) for adult rats and Lidov and Molliver (1982a,b) and Wallace and Lauder (1983) for developing rats and mice. Throughout the developing brain of MAOA knock-outs, the innervation originating in the raphe displayed a much increased 5-HT immunoreactivity, suggesting that extracellular levels of 5-HT could also be higher than in normal mice.

\section{5-HT in catecholaminergic cell groups}

As early as E12 or E15 and at least until P15 or P21, neuronal cell bodies in the substantia nigra (SN) (cell group A9), the ventral tegmental area (VTA) (A10), the retrorubral field (A8), the locus ceruleus (LC) (A6-A7), and the locus subceruleus (A5) displayed 5-HT immunolabeling in MAOA knock-outs (Table 1). In LC, cells were already intensely labeled at E12. Dendritic trees were not apparent in these neuronal populations. Double immunolabeling with antibodies to the catecholamine synthesizing enzyme $\mathrm{TH}$ showed that these 5-HT-containing neurons were catecholaminergic. The varicose 5-HT-positive terminal network contained no $\mathrm{TH}$ immunolabeling (Fig. 1). Double immunolabeling also showed that most of the TH-positive neurons contained detectable levels of 5-HT in MAOA knock-out embryos and pups, indicating that this immunolabeling was not limited to specific subpopulations of the A5-A10 catecholamine cell groups. It persisted until P28 in the dopaminergic A8-A10 cell groups, whereas it disappeared between P21 and P28 in the noradrenergic A5-A7 cell groups.

In contrast, rostral catecholaminergic cell groups were not 5-HT 
Table 2. Locations of nonaminergic 5-HT-positive fibers in the brain of MAOA knock-outs

\begin{tabular}{|c|c|c|c|c|c|c|}
\hline & $\begin{array}{l}\mathrm{E} 15 \\
n=4\end{array}$ & $\begin{array}{l}\mathrm{E} 18 \\
n=5\end{array}$ & $\begin{array}{l}\text { P0 } \\
n=6\end{array}$ & $\begin{array}{l}\text { P7 } \\
n=6\end{array}$ & $\begin{array}{l}\mathrm{P} 10 \\
n=2\end{array}$ & $\begin{array}{l}\mathrm{P} 15 \\
n=1\end{array}$ \\
\hline Orbital cortex & $a$ & $a$ & - & +++ & ++ & - \\
\hline Gustatory cortex & $a$ & $a$ & +++ & +++ & ++ & - \\
\hline Visceral cortex & $a$ & $a$ & +++ & +++ & ++ & - \\
\hline Somatosensory cortex & $a$ & $a$ & +++ & +++ & ++ & - \\
\hline Auditory cortex & $a$ & $a$ & +++ & +++ & ++ & - \\
\hline Visual cortex & $a$ & $a$ & +++ & +++ & ++ & - \\
\hline Thalamocortical tract & ++ & +++ & +++ & +++ & ++ & - \\
\hline Fimbria/Fornix & ++ & ++ & + & - & - & - \\
\hline Ventral hippocampal commissure & ++ & ++ & + & - & - & - \\
\hline Ventral fornix & ++ & ++ & - & - & - & - \\
\hline Optic chiasm and tract & +++ & +++ & +++ & ++ & + & - \\
\hline Superior colliculus & - & ++ & +++ & +++ & +++ & - \\
\hline Inferior colliculus & - & - & + & ++ & - & - \\
\hline Trigeminal tract & ++ & ++ & - & - & - & - \\
\hline
\end{tabular}

Staining intensity of fibers at prenatal and postnatal ages according to locations in the brain.

Fiber staining: - none; + light staining; ++ moderate staining; +++ heavy staining.

${ }^{a}$ Before birth, thalamocortical axons are still confined to the subplate.
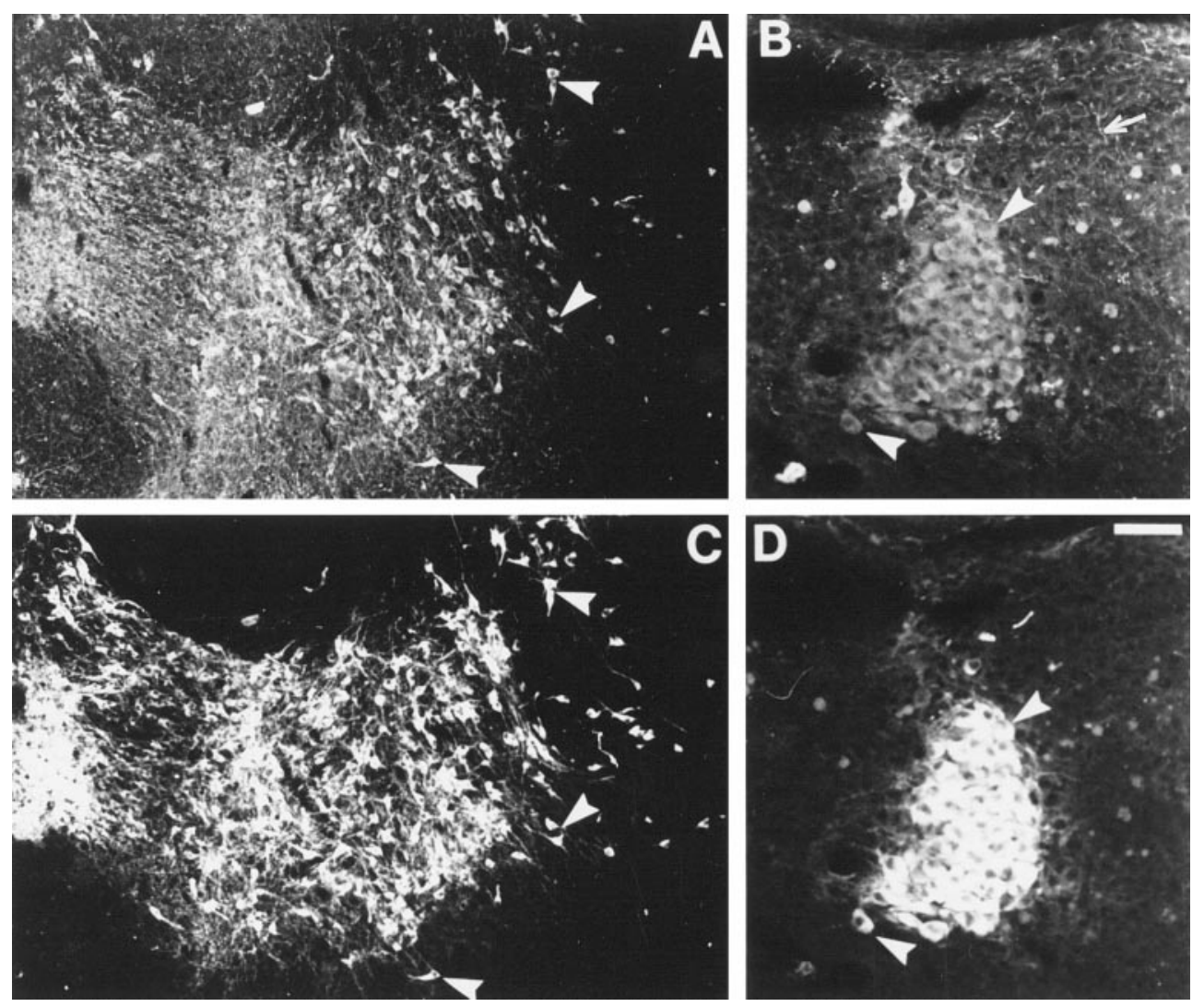

Figure 1. Catecholaminergic neurons accumulate 5-HT in P7 MAOA knockouts. Coronal section through the $\mathrm{SN}-$ VTA complex $(A, C)$ and the $\mathrm{LC}(B, D)$ were double immunostained with antibodies to 5-HT $(A, B)$ and TH $(C, D)$. As indicated by the arrowheads, almost all TH-positive neurons contain 5-HT immunolabeling. The varicose 5-HTpositive terminal network contains no TH immunolabeling (arrow). Scale bar (in $D$ ): $A, C, 140 \mu \mathrm{m} ; B, D, 50 \mu \mathrm{m}$.

immunolabeled or lightly 5-HT immunolabeled. No 5-HTcontaining neurons were observed in the olfactory bulb, whereas hypothalamic catecholaminergic cells showed moderate 5-HT immunolabeling during shorter developmental times than in the brainstem. Thus, 5-HT-containing neurons were observed in the periventricular preoptic (PVPO) and suprachiasmatic preoptic (SPO) nuclei, the paraventricular nucleus $(\mathrm{PAVH})$, and the arcuate nucleus (Arc) primarily during late embryonic life with a transient upsurge for a few neurons in the Arc between P7 and P15 (Table 1).

\section{5-HT in classically nonmonoaminergic cell groups}

\section{Telencephalon}

In normal embryos and pups, we did not observe 5-HTimmunolabeled cell bodies in the telencephalon (Fig. $2 A, C$ ). In contrast, MAOA knock-out embryos and pups displayed 5-HTcontaining neurons in cortical, hippocampal, or amygdaloid areas.

By E18, 5-HT-containing neurons were observed in the anterior cingulate cortex (ACG) in both its supra and pregenual parts 
Figure 2. Atypical locations of 5-HT accumulation in the telencephalon of E18 MAOA knock-outs. Coronal brain sections are shown for controls $(A, C)$ and MAOA knock-outs $(B, D-G)$. $A$, In controls, 5-HTimmunostained fibers are primarily observed in the medial forebrain bundle $(M F B)$. B, In MAOA knock-outs, 5-HT immunostaining of the MFB is increased, and a dense 5-HT immunolabeling is visible in the nucleus reticularis $(R T)$, the thalamocortical fibers in the internal capsule (IC), the hippocampus $(H I)$, and the amygdala $(A M G)$. A higher magnification of the medial cortical area is shown in $C$ and $D$ at a more rostral level through the corpus callosum $(C C)$, anterior cingulate cortex $(A C G)$, and indusium griseum $(I G) . C$, In controls, 5-HT immunoreactivity is only observed in terminal fibers or fiber tracts in the septum and ACG; the 5-HT-positive fibers in ACG form a bilaminar pattern in layer I and in the deep cortical layers. $D$, In MAOA knock-outs, 5-HT-positive fibers are more intensely stained, and additional labeling is visible in the fornix $(F X)$ and in neuronal cell bodies in ACG and IG. $E$, A closer view of the 5-HT-immunolabeled cell bodies in the hippocampus reveals that these neurons have the morphological aspect of the principal pyramidal cells. Arrow indicates a neuron with a clear labeling of the dendritic tree. $F$, A closer view of the 5-HT immunolabeled neurons in the central nucleus of the amygdala. Arrows indicate neurons having a typical ovoid shape. $G$, Higher magnification of the 5-HT-positive thalamocortical fibers as they reach the cortical primordium. A dense network of fibers (fiber tracts and varicose fibers) is observed in the subplate $(S P)$, with some fibers (open arrows) starting to penetrate in the cortical plate $(C P)$. In contrast, a few long varicose fibers (arrow), probably representing afferents from the raphe, run in the intermediate zone (IZ). Only varicose fibers in SP and IZ were 5-HT immunoreactive in control mice, and this staining was much less intense than in MAOA knock-outs. $V Z$, Ventricular zone. Scale bar (in $G$ ): $A, B, 625 \mu \mathrm{m} ; C, D, 150$ $\mu \mathrm{m} ; E, 27 \mu \mathrm{m} ; F, 40 \mu \mathrm{m} ; G, 33 \mu \mathrm{m}$.
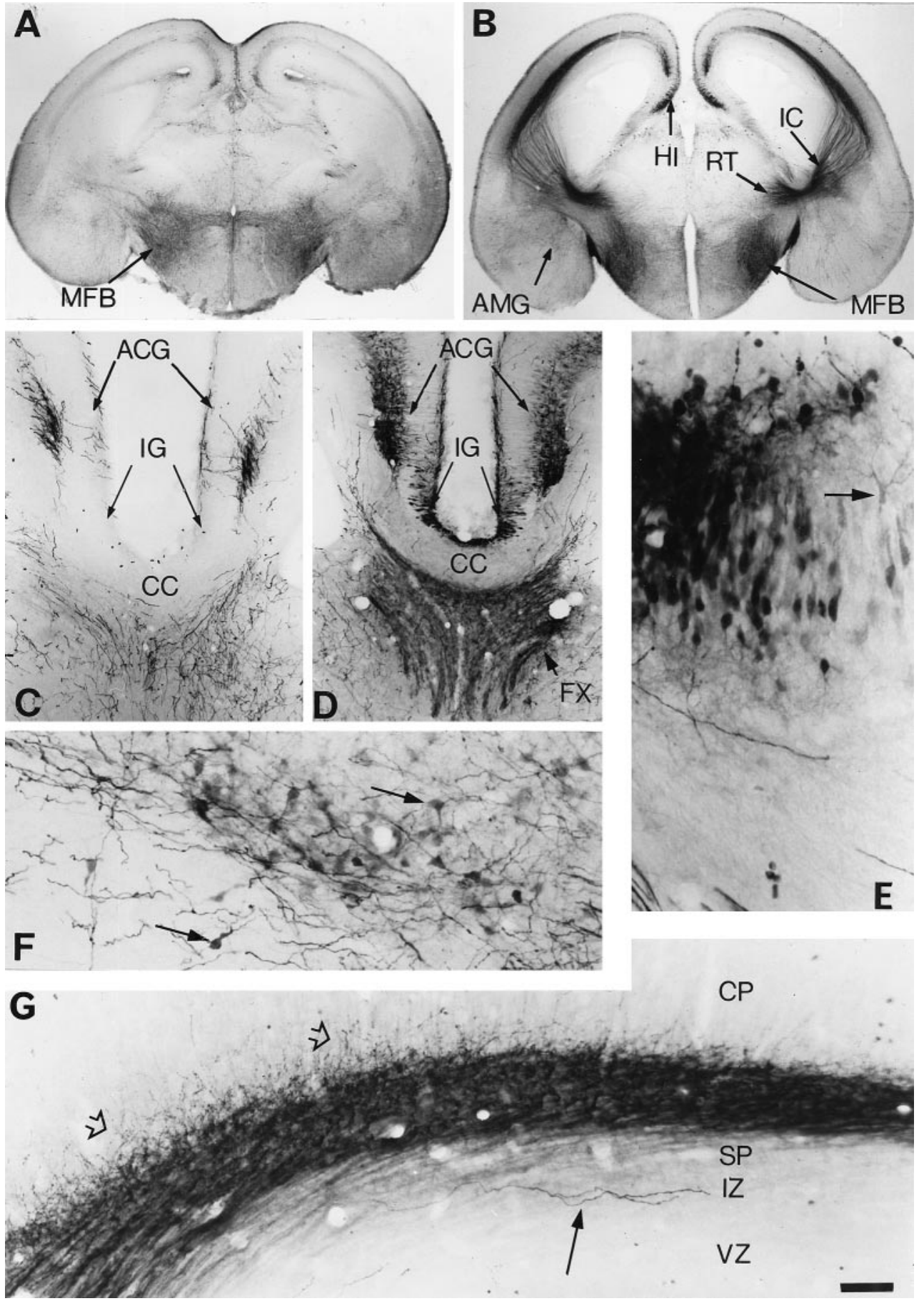

(Fig. 2B,D) and in the granular (RSG) and agranular (RSA) retrosplenial cortex (Table 1 ). Their labeling generally appeared to be of medium intensity and was visible during late embryonic life until birth in RSG and RSA and until P10 in ACG (Fig. 3A). These 5-HT-containing neurons were located in the deep cortical layers (V-VI) and had the morphological appearance of pyramidal neurons (Fig. 3C). In normal mice, the corresponding cortical areas only displayed a dense network of thick serotonergic axons arranged in a bilaminar array (Fig. $2 A, C$ ).

By E17, 5-HT-containing neurons were observed in the hippocampal primordium. Their number sharply decreased by P0 (Table 1). As identified by the light 5-HT immunolabeling of their main dendrites, these neurons were pyramidal neurons in the indusium griseum (Fig. 2D) and in the CA1 and CA3 hippocampal fields (Fig. 2B,E). The efferent projections of these neurons most likely correspond to 5-HT-immunolabeled bundles observed in the fimbria, the ventral hippocampal commissure (containing the crossed projections from CA3 neurons), and the dorsal fornix from E18 to P0 (Fig. 2D). The subiculum, the other major output region of the hippocampal formation, did not show 5-HTcontaining neurons. However, axons projecting through the ventral fornix known to contain subicular efferents appeared lightly 5-HT positive between E15 and E19. Correspondingly, pyramidal neurons in the dorsal subiculum, a projection area for the CA1 

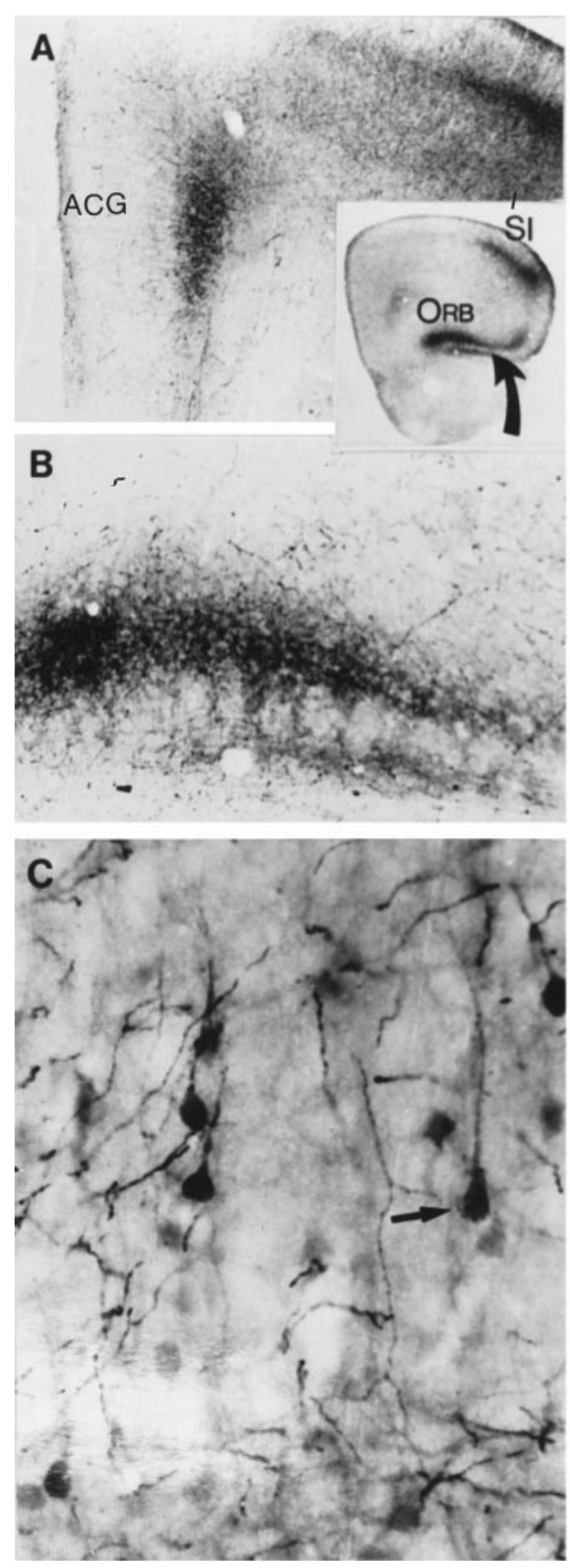

D
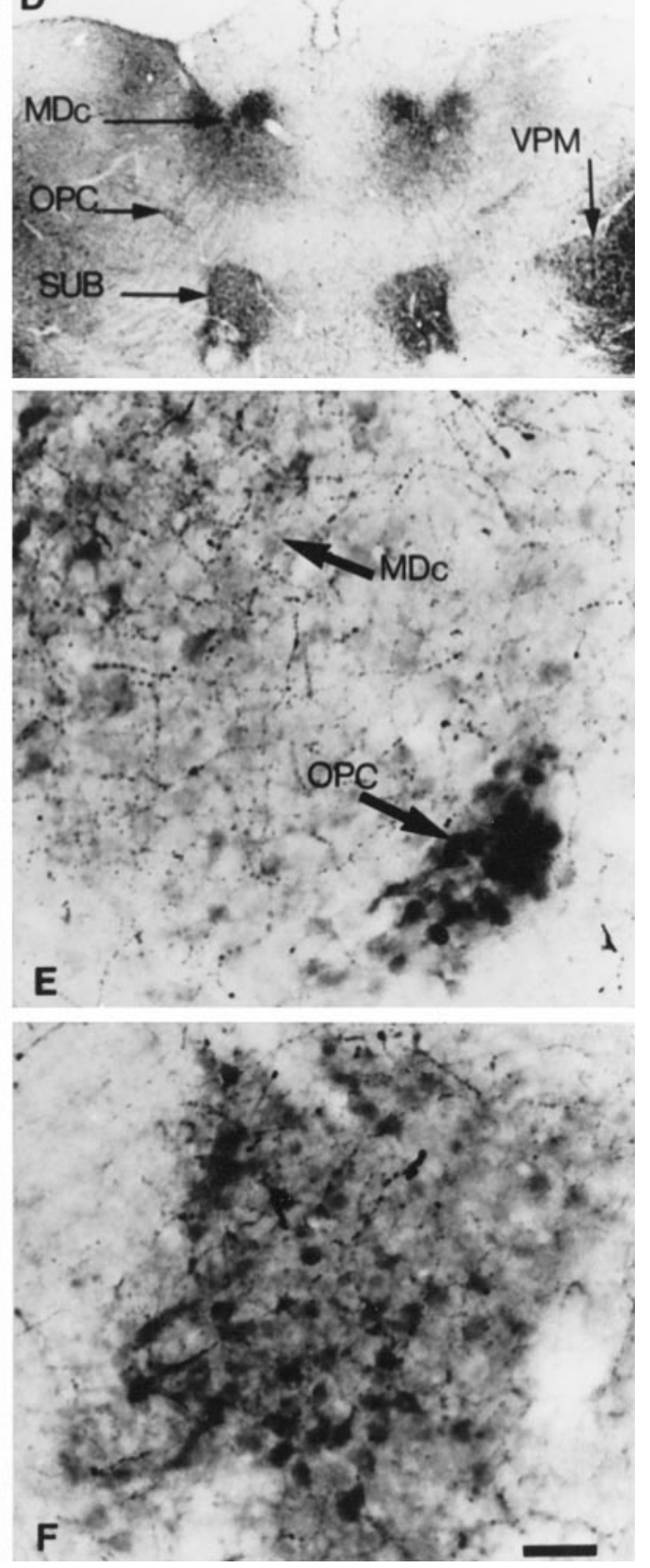

Figure 3. Atypical locations of 5-HT accumulation in the forebrain of $\mathrm{P} 7$ MAOA knock-outs. $A$, The coronal section through the frontal cortex shown in the inset indicates the position of unusual 5-HT immunolabeling in the orbital cortex $(O R B)$ ventrally (curved arrow) and in the medial prefrontal and pregenual anterior cingulate cortex $(A C G)$ medially; the primary somatosensory cortex $(S I)$ was shown previously to be 5-HTlabeled in normal pups. $B$, At higher magnification, 5-HT immunolabeling in the orbital cortex is seen to be localized in a plexus of fine fibers in layer III. $C$, Higher magnification shows the presence of 5-HT-containing neurons in ACG. Arrow points to a neuron with a typical pyramidal shape. $D$, Coronal section through the thalamus showing strong 5-HT-immunolabeling in different thalamic nuclei. $M D c$, Central part of the mediodorsal nucleus; $S U B$, submedial nucleus; $O P C$, oval paracentral nucleus; $V P M$, ventroposteromedial nucleus. $E$, Higher magnification shows the presence of 5-HT-immunolabeled cell bodies in MDc and OPC. F, Higher magnification shows the presence of 5-HT-immunolabeled cell bodies in SUB. Scale bar (in E): inset, $820 \mu \mathrm{m} ; A, B, D, 150 \mu \mathrm{m} ; C, 19$ $\mu \mathrm{m} ; E, F, 24 \mu \mathrm{m}$. pyramidal neurons, showed transient expression of SERT mRNA (Lebrand et al., 1998).

Finally, 5-HT-containing neurons were observed at the periphery of the central nucleus of the developing amygdala between E15 and P0 (Table 1). These neurons had a piriform shape with generally two to three primary dendrites and displayed medium to intense 5-HT immunolabeling (Fig. $2 F$ ).

\section{Diencephalon}

5-HT-containing cell bodies were found in primary sensory thalamic nuclei of the diencephalon of normal mice essentially between P4 and P7. In MAOA knock-outs, 5-HT immunolabeling was also seen in embryos and pups in other thalamic nuclei and in the suprachiasmatic nucleus.

Thalamus. We have shown previously that in normal pups, neurons in the somatosensory ventroposterolateral (VPL) and ventroposteromedial (VPM) nuclei, the visual dorsal lateral geniculate nucleus (DLG), and the auditory ventral medial geniculate nucleus (MGV) are transiently 5-HT immunoreactive (Lebrand et al., 1996). The 5-HT immunolabeling of these thalamic neurons was considerably increased in MAOA knock-outs of corresponding ages. While in normal mice the 5-HT immunolabeling is concentrated in the axonal compartment with only a faint diff use labeling of the cell bodies, MAOA knock-outs displayed a clear and intense immunostaining of both individual cell bodies and axons running in the internal capsule or projecting to the reticular thalamic nucleus. Furthermore, the 5-HT immunolabeling was visible over a larger developmental period than in controls. In normal pups, 5-HT immunolabeling was noted at P4 and $\mathrm{P} 7$ in cell bodies and at $\mathrm{P} 0, \mathrm{P} 7$, and $\mathrm{P} 10$ in thalamocortical 
fibers. In MAOA knock-outs, it was noted already at the earliest embryonic age examined (E15) in VPL and DLG and persisted until P15 (Table 1).

MAOA knock-outs displayed neuronal labeling in additional nuclei (Table 1). The visceral parvicellular part of VPL and the gustatory parvicellular part of the VPM displayed very strong 5-HT immunolabeling. Less intensely labeled neurons were observed in the central part of the mediodorsal nucleus (MDc) (Fig. $3 D, E$ ), the nociceptive submedial nucleus (SUB) (Fig. $3 D, F$ ), the oval paracentral nucleus (Fig. $3 D, E$ ), the rostral part of the posterior nucleus, the centrolateral nucleus (small patches of cells), the rostrolateral part of the lateral posterior nucleus, and the dorsal and medial parts of the medial geniculate nucleus (Table 1).

Sensory thalamocortical axons arising from the dorsal thalamus displayed intense 5-HT immunolabeling in MAOA knock-outs as early as E15 (at P0 in normal mice) (Table 2). By E18, the 5-HT immunolabeled thalamocortical axons reach the subplate through the internal capsule forming a dense plexus in the subplate (Fig. $2 B, G$, see also $5 C$ ). Later in development, a dense plexus was visible in the layers IV and VI of the primary somatosensory, auditory, visual, gustatory, and visceral cortices (Table 2). A plexus of moderate density was visible in the secondary somatosensory, auditory, and visual cortices between P4 and P10. Projections from the MDc and SUB were labeled in layer II-III of the lateral and ventral orbital cortex (Fig. 3B; Table 2) between P4 and P10, whereas a 5-HT-positive plexus was not observed in this part of the cortex in normal mice.

Hypothalamus. 5-HT-containing neurons were observed in the ventral and medial zones of the suprachiasmatic nucleus (SCN) during a protracted period of postnatal life (Table 1), whereas only a dense serotonergic innervation was present in normal mice (van den Pol and Tsujimoto, 1985; van den Pol, 1986). A positive correlation was found between the amount of label in individual cell bodies and the number or size of the 5-HT varicosities in close contact with the soma.

\section{Brainstem}

In MAOA knock-outs, 5-HT-containing neurons were observed in two auditory relays, the anteroventral cochlear nucleus and the lateral superior olivary nucleus (LSO) (Fig. 4A, Table 1). The major auditory center, the inferior colliculus (IC), did not contain 5-HT-positive cell bodies. In LSO, the 5-HT-positive cell bodies were in the lateral and central parts of the nucleus, as determined by counterstaining with methyl green, and immunostaining increased from central to lateral along the tonotopic axis. During the same period, 5-HT-positive bundles of fibers entering the IC and a dense 5-HT-positive plexus in the central nucleus of the IC were also observed (Fig. 4B,D, Table 2). The distribution resembled that of LSO efferent fibers.

In the somatosensory pathway, 5-HT immunolabeling was not observed in neurons of the principal nucleus of the trigeminal, although primary sensory fibers entering this nucleus were transiently 5-HT immunolabeled (our unpublished observations) (Table 2). Retinal afferents were transiently 5-HT immunolabeled (Figs. 4B, 5C; Table 2) (Upton et al., 1997; our unpublished observations). Other projections from peripheral neurons were 5-HT immunoreactive and will be described in separate reports (our unpublished observations).

\section{AADC in 5-HT-containing neurons}

The presence of 5-HT in atypical locations in developing mice could reflect a local synthesis of 5-HT. We determined whether the biosynthetic enzyme AADC is present at these sites at E18, P0, P7, P10, and P21 in MAOA knock-outs and normal controls. At all ages, the AADC immunolabeling was normally localized in the serotonergic, noradrenergic, and dopaminergic cell bodies and fibers, as well as in the 14 "D" groups of AADC-expressing cells (for review, see Jaeger et al., 1984). No AADC-containing neurons were observed in the cortex, amygdala, hippocampal formation, and thalamus (Fig. 5A, $B, D$ ). 5-HT-containing neurons in LSO and the anteroventral cochlear nucleus also lacked AADC.

\section{Pharmacological treatments with inhibitors of transporters}

To determine whether the 5-HT immunolabeling is caused by an uptake of 5-HT, MAOA knock-outs were injected with inhibitors of the monoaminergic transporters. Repeated administration of fluoxetine, a selective inhibitor of 5-HT uptake, to pregnant MAOA knock-out dams $(30 \mathrm{mg} / \mathrm{kg}$, seven injections at $4 \mathrm{hr}$ intervals) completely eliminated 5-HT-immunolabeling in the nonaminergic 5-HT-containing neurons of the cortex, hippocampus, thalamus, and LSO of E19 embryos without affecting 5-HT immunolabeling in the catecholaminergic cell groups (data not shown). Similarly, in P7 MAOA knock-outs, repeated administration (three injections at $10 \mathrm{hr}$ intervals) of the SERT inhibitors fluoxetine $(30 \mathrm{mg} / \mathrm{kg})$ or paroxetine $(50 \mathrm{mg} / \mathrm{kg})$ abolished 5-HT immunolabeling in all the thalamic nuclei and in the corresponding cortical projection areas (Fig. 6C), although a very faint labeling was still observed in the thalamocortical fibers in the internal capsule and in a few cell bodies. In contrast, fluoxetine or paroxetine treatments increased 5-HT immunolabeling in all the catecholaminergic cell groups (even after a single injection $6 \mathrm{hr}$ before perfusion) (Fig. 6A,B). It was particularly apparent for Arc neurons (Fig. 7A) and for SN neurons and $\mathrm{SN}$ axonal terminals. Indeed, a fine 5-HT immunolabeled network was readily visible in the striatum after such treatments. Nisoxetine (10 or 30 $\mathrm{mg} / \mathrm{kg}$, two injections), a selective inhibitor of norepinephrine uptake, eliminated 5-HT immunolabeling in noradrenergic neurons (Fig. 6D) without affecting 5-HT immunolabeling in $\mathrm{SN}$ (Fig. 6E) and thalamic nuclei (Fig. 6F). GBR12783 (10 or 30 $\mathrm{mg} / \mathrm{kg}$, two injections), a selective inhibitor of dopamine uptake, abolished 5-HT immunolabeling in dopaminergic neurons (Fig. $6 H$ ) without affecting 5-HT immunolabeling in LC (Fig. 6G) or thalamic nuclei (Fig. 6I). Curiously, neither blocking 5-HT uptake with fluoxetine nor blocking catecholamine uptake with GBR12783 or nisoxetine could diminish the number of 5-HTcontaining neurons in SCN. On the contrary, fluoxetine or paroxetine treatments enhanced neuronal staining in SCN (Fig. 7B). Treatment with NO-711 (50 mg/kg, three injections), a specific inhibitor of GAT-1, a neuronal GABA transporter that shares structural similarities with monoaminergic transporters, did not diminish the number of 5-HT-containing neurons in SCN.

\section{MAOA-DAT double knock-out mice}

We generated double knock-outs by crossing MAOA knock-outs and DAT knock-out mice (Giros et al., 1996). In contrast to MAOA knock-outs, MAOA-DAT double knock-out mice showed a total lack of 5-HT immunolabeling in the dopaminergic neurons of the SN-VTN complex (Fig. 8), PAVH, and Arc between E16 and P7, whereas 5-HT immunolabeling was main- 

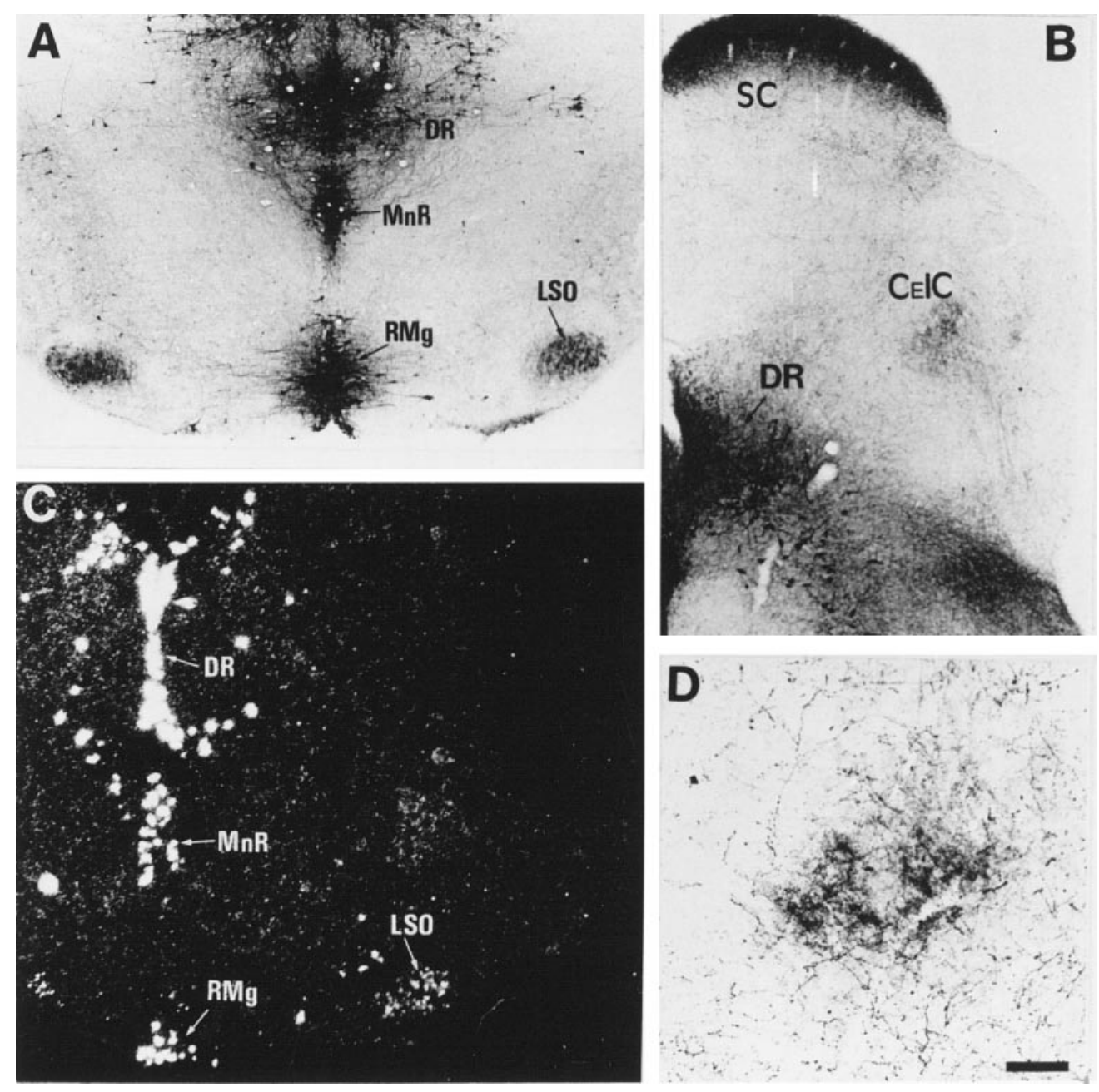

Figure 4. 5-HT uptake in neurons of the LSO. Coronal sections through the brainstem of P7 MAOA knock-outs $(A, B, D)$ and control $(C)$. $A, 5$-HT immunoreactivity is normally localized in 5-HT-producing neurons of the dorsal raphe $(D R)$, median raphe $(M n R)$, and raphe magnus $(R M g)$ and is abnormally localized in auditory neurons of LSO. B, 5-HT immunolabeling is found in the projection area of LSO neurons in the central nucleus of the inferior colliculus $(C E I C)$. See higher magnification in D. 5-HT immunolabeling is also visible in the stratum zonale and stratum griseum of the superior colliculus $(S C)$ and is primarily contained in retinal afferents (A. L. Upton, N. Salichon, I. Seif, and P. Gaspar, personal communication). $C$, In situ hybridization with a radiolabeled SERT riboprobe shows the presence of SERT RNA in LSO neurons and in the raphe nuclei. $D$, At higher magnification, 5-HT immunolabeling in CEIC is not seen in cell bodies but in auditory afferents, presumably from LSO, as suggested by the trajectory of corresponding fiber bundles in adjacent sections. Scale bar (in $D$ ): $A-C, 200 \mu \mathrm{m} ; D, 80 \mu \mathrm{m}$.

tained in LC (Fig. 8), MGV (Fig. 8), and the other thalamic nuclei, and SCN (data not shown) 5-HT immunolabeling was also maintained in PVSO, SPO, and SCN (data not shown).

Using MAOA-DAT double knock-out pups, we determined whether the previously reported behavioral abnormalities of MAOA single knock-out pups, such as tremor, myoclonus, agitation, frantic running, biting, and abnormal postures (Cases et al., 1995), could be related to the presence of 5-HT in dopamine neurons. MAOA-DAT double knock-out pups, but not DAT single knock-out pups, displayed the same behavioral abnormalities as MAOA single knock-out pups. Conversely, MAOA-DAT double knock-outs, but not MAOA single knock-outs, showed the same lethality as DAT single knock-outs at weaning age, which was prevented in both cases by supplementing the diet with hydrated food.

\section{SERT RNA in nonmonoaminergic 5-HT-containing neurons}

In a companion study using in situ hybridization and immunocytochemistry (Lebrand et al., 1998), we have analyzed the spatio- temporal expression patterns of SERT, DAT, and NET in developing normal mice, focusing on the forebrain and catecholaminergic groups. These normal patterns proved to be in good agreement with our spatiotemporal and pharmacological analyses of 5-HT accumulation in MAOA knock-outs. All of the nonmonoaminergic 5-HT-containing neurons observed in the forebrain of MAOA knock-outs appeared to transiently express SERT RNA in normal mice, except the amygdala and SCN neurons, in which no RNA expression of SERT, DAT, or NET could be found. Similarly, normal brainstem and midbrain catecholaminergic neurons did not show SERT RNA expression, whereas they expressed DAT or NET RNA abundantly. Here, we show additionally that SERT RNA is expressed in neurons of the LSO in normal mice (Fig. 4C).

\section{DISCUSSION}

In this report, we describe that in the developing CNS of MAOA knock-outs, 5-HT immunoreactivity is abnormally and transiently localized in catecholaminergic and nonmonoaminergic neurons. 
Figure 5. Immunocytochemical localization of AADC in E18 MAOA knock-outs. $A, B$, As viewed on coronal brain sections from rostral $(A)$ to caudal $(B)$, AADC immunoreactivity is localized in terminal fibers in the striatum, cortex, and hippocampus and in fiber tracts in the MFB or stria terminalis. AADC immunostaining of perikarya appears to be limited to catecholaminergic and D-group (Jaeger et al., 1984) neurons in the hypothalamus (HYP ). C, D, Coronal sections at comparable levels of the diencephalon are shown with 5-HT $(C)$ and AADC immunostaining $(D)$; both antisera label fibers in the MFB. On the other hand, the dense 5-HT immunolabeling of the ventroposterior complex $(V P)$, dorsal lateral geniculate nucleus $(D L G)$, thalamocortical fibers $(T A)$, and optic tract $(O P)$ has no visible counterpart with AADC immunostaining. Scale bar (in $D$ ): $A-D, 625 \mu \mathrm{m}$.
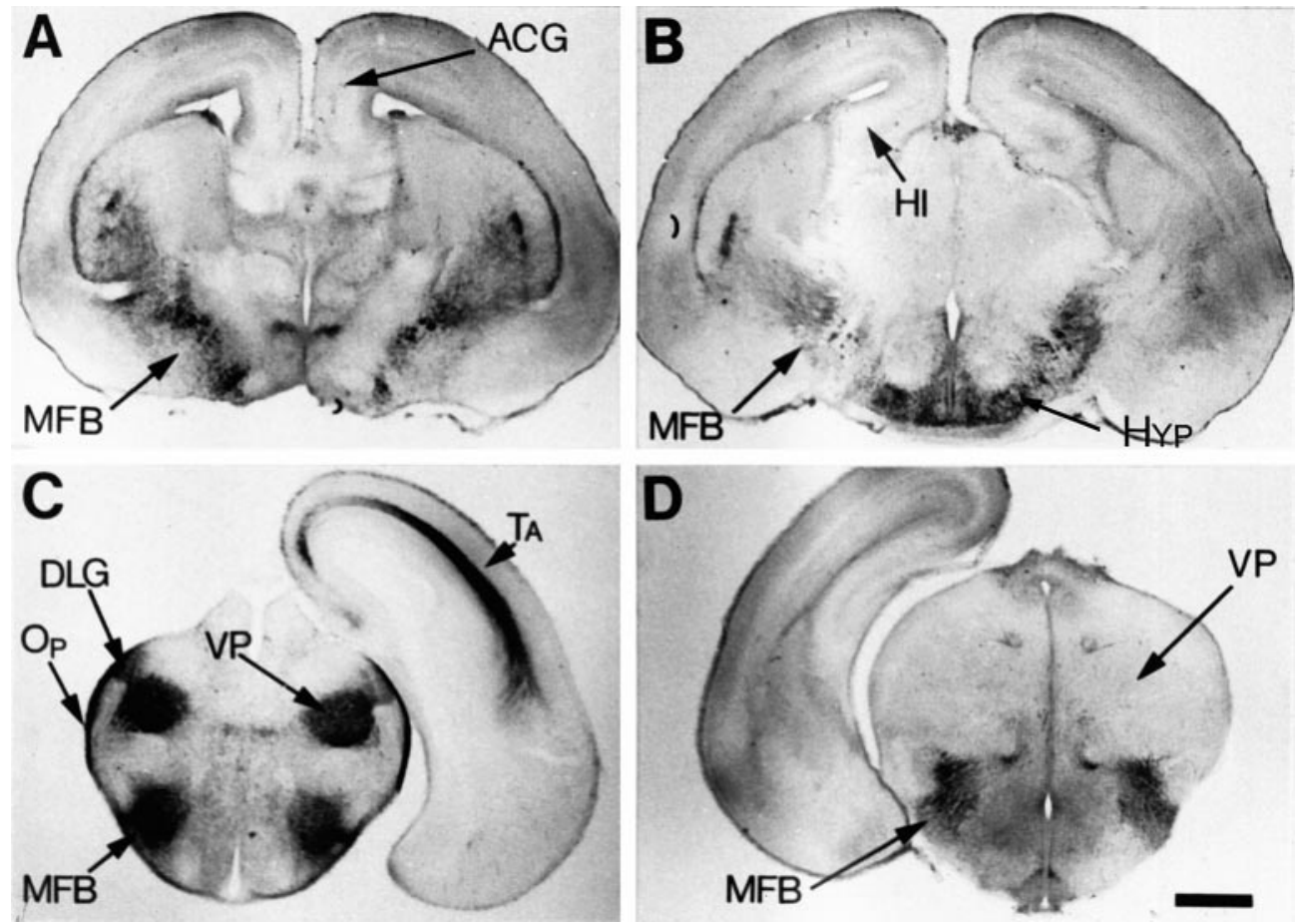

This is attributable to the lack of the normal degradation pathway of 5-HT and to the existence of functional transport of 5-HT, either by SERT, which is transiently expressed in nonmonoaminergic neurons, or by DAT and NET in catecholaminergic neurons. These abnormal accumulations of 5-HT during development could underlie some of the developmental and behavioral abnormalities that are observed in MAOA knock-outs (Cases et al., 1995).

\section{Mechanisms of 5-HT accumulation in MAOA knock-outs}

Early descriptions of rodent serotonergic systems in adult (Steinbusch, 1981) or during development (Lidov and Molliver, 1982a,b; Wallace and Lauder, 1983) have localized 5-HT exclusively in the neurons of the raphe complex (B1-B9) and in their widespread axonal arbors throughout the brain and spinal cord. However, recent studies during early postnatal development have questioned this view by showing that the transient dense 5-HT innervation of the primary somatosensory, visual, and auditory cortices (Fujimiya et al., 1986; D'Amato et al., 1987; Rhoades et al., 1990) is related to a 5-HT uptake in the corresponding thalamocortical neurons (Lebrand et al., 1996). This 5-HT uptake in developing thalamic neurons is attributable to the transient expression of SERT. More recent studies with in situ hybridization (Hansson et al., 1998; Lebrand et al., 1998) or autoradiographic binding (Bruning et al., 1997) have shown extensive sites of SERT expression during CNS development, both in the diencephalon and the telencephalon, and there appears to be an excellent correlation between the spatiotemporal pattern of SERT expression and 5-HT accumulation patterns that are detected in MAOA knock-outs in the cortex, hippocampus, and thalamus. The demonstration that 5-HT is only taken up but is not synthesized locally in these neurons is established by the lack of AADC, the last biosynthetic enzyme in the 5-HT biosynthesis pathway, in the developing cortical, hippocampal, or thalamic neurons. Furthermore, the 5-HT labeling of these structures was abolished by selective inhibitors of 5-HT uptake such as fluoxetine or paroxetine. It is noteworthy that these uptake inhibitors had to be administered repeatedly and at least during $24 \mathrm{hr}$ to abolish the immunolabeling of the large thalamocortical fibers at $\mathrm{P7}$, suggesting that 5-HT can be extremely resilient in neurons that lack MAOA. This resilience may be partly linked to a storage of 5-HT into vesicles via the vesicular monoamine transporter VMAT2, because VMAT2 RNA expression is observed in thalamic sensory neurons (Lebrand et al., 1996). If 5-HT was indeed stored into synaptic vesicles in these neurons, it could be released in an activity-dependent manner in normal mice. In MAOA knock-outs, such a release could be blocked by excess extracellular 5 -HT acting on the inhibitory $5-\mathrm{HT}_{1 \mathrm{~B}}$ receptors that are present on thalamocortical fibers (Rhoades et al., 1994); this would counterbalance the lack of 5-HT replenishment during fluoxetine treatments. In comparison with MAOA knock-outs, normal mice displayed a much more limited 5-HT immunolabeling; 5-HT was not detected in any of the neurons that transiently express SERT during embryonic life, and during postnatal life, 5-HT was only sometimes visible in primary sensory thalamic cell bodies but was never observed in the other dorsal thalamic neurons, cortex, or hippocampus. These observations suggest that in normal conditions 5-HT is rapidly degraded in these neurons or is present in a labile compartment with a rapid turnover (e.g., immediate release and degradation in the extracellular space).

Besides the 5-HT accumulation in the neurons that transiently express SERT, MAOA knock-outs accumulated 5-HT in the major catecholaminergic cell groups of the brainstem and hypothalamus. This accumulation is mediated by DAT in the A8-A10 dopaminergic complex and in the hypothalamic PAVH and Arc, as demonstrated after pharmacological treatments and our observations in double knock-out mice that lack both DAT and MAOA. In the noradrenergic cell groups, 5-HT is taken up through NET, as indicated by our pharmacological blocking experiments. Previous pharmacological studies in vitro have shown 

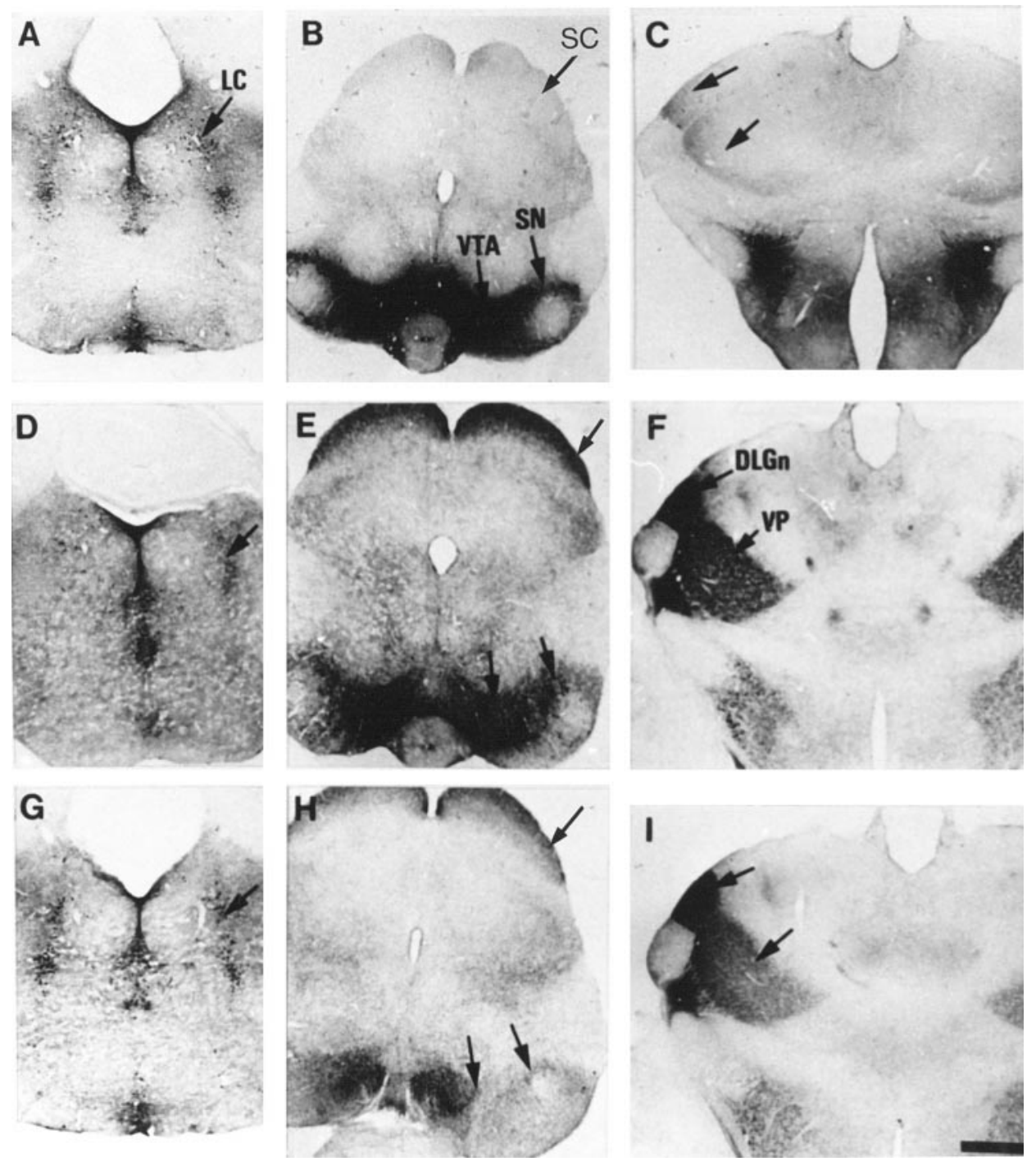

Figure 6. Changes of 5-HT immunoreactivity in P7 MAOA knock-outs after administration of selective inhibitors of monoaminergic transporters. Comparable coronal brain sections are shown in the metencephalon $(A, D, G)$, mesencephalon $(B, E, H)$, and diencephalon $(C, F, I)$, after repeated administration of fluoxetine $(A-C)$, nisoxetine $(D-F)$, or GBR12783 $(G-I)$ at P6 and P7. Control brain sections obtained from untreated MAOA knock-outs are not shown. 5-HT immunolabeling of the raphe nuclei is not visibly affected by any pharmacological treatment, although the staining of the fine varicose afferents from the raphe is reduced by the fluoxetine treatment. $A-C$, Fluoxetine, a selective inhibitor of SERT, causes the disappearance of 5-HT immunolabeling in the SC $(B)$ and thalamus at the level of DLGn and VP $(C)$ but increases staining of dopaminergic neurons in the $\mathrm{SN}$ and VTA $(B)$, with no visible change in the $\operatorname{LC}(A)$. $D-F$, Nisoxetine, a selective inhibitor of NET, greatly reduces 5-HT immunolabeling in the $\mathrm{LC}(D)$ but does not cause changes of staining in the SN, VTA, SC $(E)$, or thalamus $(F)$. $G-I$, GBR12783, a selective inhibitor of DAT, abolishes 5-HT immunolabeling in the SN and VTA $(H)$ but not in the LC $(G)$, SC $(H)$, or thalamus $(I)$. Scale bar (in $I$ ): $A-I, 625 \mu \mathrm{m}$. that in transfected cell lines expressing DAT or NET, 5-HT cannot competitively inhibit catecholamine uptake (Giros et al., 1991; Pacholczyk et al., 1991). However, the kinetics of 5-HT transport in such cell lines have not been investigated, and the possibility should be considered that in native monoaminergic neurons, transporters have higher affinities for 5-HT than in in vitro expression systems.

Shaskan and Snyder (1970) showed that brain slices of striatum and hypothalamus displayed both high- and low-affinity uptake sites for 5-HT and suggested that the low-affinity uptake reflected an uptake in catecholaminergic terminals. Similar observations were made in autoradiographic studies after uptake of tritiated monoamines in brain slices (Berger and Glowinski, 1978; Doucet et al., 1988). In vivo, 5-HT accumulation was noted in dopaminergic neurons of the SN (Steinbush et al., 1982), hypothalamus (Lichtensteiger et al., 1967; ChanPalay, 1977; Beaudet and Descarries, 1979), and pituitary intermediate lobe (Vanhatalo and Soinila, 1994) after supplementing animals with exogenous 5-HT or the 5-HT precursor L-tryptophan and blocking 5-HT degradation with inhibitors of monoamine oxidases. Arai et al. (1995) showed that when adult rats are injected with the 5-HT precursor 5-hydroxytryptophan (5-HTP), 5-HT accumulates in SN neurons, whether MAO inhibitors are added or not. They concluded that 5-HT was synthesized by the SN neurons (although it was not investigated whether DAT plays a role in this 5-HTP effect) and that the amine was not rapidly degraded in these neurons. The latter observation suggests that in MAOA knock-outs, increased extracellular levels of 5-HT surrounding SN neurons could be more critical than the lack of 5-HT degradation by MAOA in these neurons. In any case, in MAOA knock-outs, the intensity of 5-HT immunolabeling in individual SN neurons appeared to correlate with the abundance of 5-HT terminal innervation in close association with the cell body. It is not known whether within these structures rich in extracellular 5-HT the density of DAT sites on the surface of the dopaminergic cell body is high enough to cause an efficient uptake of 5-HT. Quite the opposite, it has been reported that DAT is primarily localized to dendritic and axonal plasma membranes (Ciliax et al., 1995; Nirenberg et al., 1997), although this was studied in adult rats, and it is known that DAT expression varies with age (Coulter et al., 1996).

5-HT immunolabeling in catecholaminergic neurons was observed as early as E12 in MAOA embryos. This suggests efficient release of 5-HT from raphe fibers at E12, as well as efficient DAT and NET uptake at this age. In postnatal MAOA knock-outs, the 

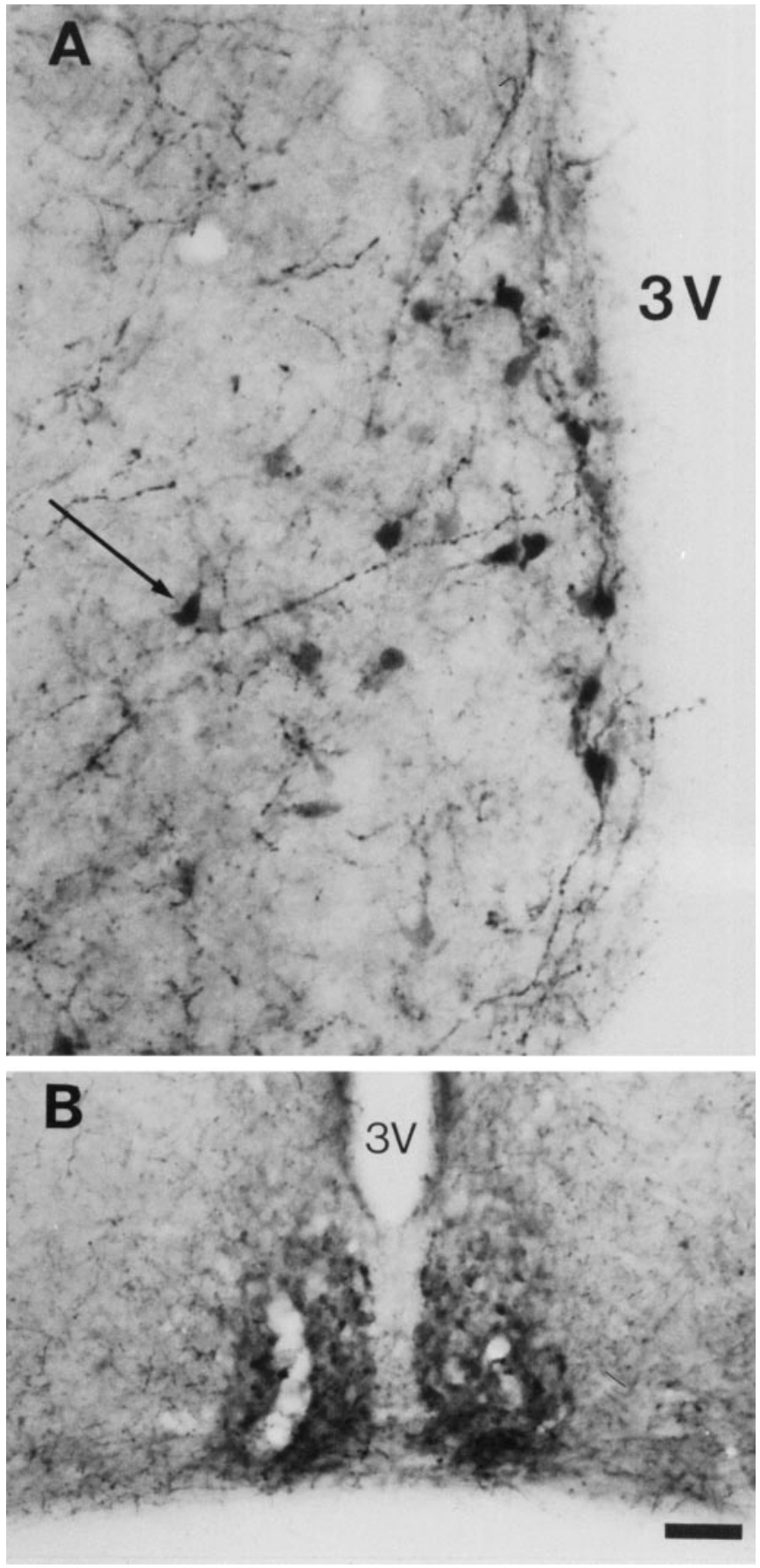

Figure 7. Increase in the number of 5-HT-containing neurons in the hypothalamus of P7 MAOA knock-outs after fluoxetine treatments. Control brain sections obtained from untreated MAOA knock-outs are not shown. $A$, The number of 5-HT-containing neurons is increased in the Arc. Arrow indicates a dorsal periventricular neuron. $B$, The number of 5-HT-containing neurons is increased in the SCN. $3 V$, Third ventricle. Scale bar (in $B$ ): $A, 24 \mu \mathrm{m} ; B, 90 \mu \mathrm{m}$.

5-HT-immunolabeling of catecholaminergic neurons was noted only during the first 3 weeks of postnatal life when brain 5-HT levels are highest (Cases et al., 1995). Thereafter, 5-HT immunolabeling diminished and eventually disappeared in catecholaminergic neurons, in relationship with the relative normalization of 5-HT levels because of the compensatory activity of the monoamine oxidase $\mathrm{B}$ (MAOB), possibly in association with intervening glial processes. When MAOB activity was pharmacologically inhibited in 5-month-old MAOA knock-outs, the 5-HT immunolabeling of catecholaminergic neurons reappeared (our unpublished observations).

One developmental localization of 5-HT in MAOA knock-outs that could not be clarified by the present pharmacological blocking experiments is the localization of 5-HT in neurons of the ventral and medial zones of the SCN. No SERT, DAT, or NET expression has been detected in these neurons (Lebrand et al., 1998). However, a very low expression of SERT might be sufficient, because 5-HT-labeled neurons in SCN benefit from an abundant 5-HT innervation originating in the raphe, and our pharmacological treatments cannot achieve total inhibition of SERT. Alternatively, 5-HT could be taken up by another transporter, such as a putative melatonin transporter (Helton et al., 1993; Liu et al., 1997).

\section{Functional consequences of 5-HT accumulation in MAOA knock-outs}

The functional consequences of 5-HT accumulation in the catecholaminergic neurons of MAOA knock-outs could not be predicted. Comparison of MAOA-DAT double knock-outs and MAOA single knock-outs failed to reveal developmental or behavioral consequences of 5-HT accumulation in dopaminergic neurons. MAOA-DAT double knock-outs lacked cortical barrels (our unpublished observations). Similarly, MAOA-DAT double knock-out pups displayed the flagrant behavioral abnormalities of MAOA knock-out pups (Cases et al., 1995), such as trembling. In fact, 5-HT accumulation in catecholaminergic neurons could be less detrimental to catecholaminergic function than the presence of excess extracellular 5-HT.

A particularly important feature of the spatiotemporal pattern of nonmonoaminergic 5-HT-containing neurons in MAOA knock-outs is the preferential localization of 5-HT uptake to glutamatergic neurons that form precise projection maps, which may be regarded as an indirect indication that extracellular 5-HT levels modulate the formation of these maps. We have described previously that somatosensory thalamocortical fibers, which accumulate large amounts of 5-HT in MAOA knock-out pups, develop abnormally, because they do not form proper axonal branches and barrel clusters in layer IV of the somatosensory cortex (Cases et al., 1996). Remarkably, as shown in the present report, thalamocortical fibers take up 5-HT from their initial outgrowth in MAOA knock-out embryos. This suggests that in normal mice, 5-HT has an effect on these fibers before they reach their specific cortical targets. However, in MAOA knock-outs, excess 5-HT does not seem to disrupt the major embryonic guidance mechanisms of the somatosensory thalamic fibers, because a normal barrel pattern can be obtained by decreasing 5-HT levels postnatally.

As in the case of the somatosensory cortex, postnatal alterations could be expected to occur in the primary visual, auditory, gustatory, and visceral thalamocortical projections that also display intense 5-HT accumulation during a critical period of their development. The presence of 5-HT immunoreactivity in neurons of the SUB, which relays thermoceptive and nociceptive information (Yoshida et al., 1991, 1992; Roberts and Dong, 1994), and in neurons of the central part of the MDc, which receives inputs from olfactory-related structures (Price and Slotnick, 1983; Groenewegen et al., 1990), also suggests that these thalamic neurons have a critical period during which the spatial tuning of their projections to the orbital cortex is sensitive to $5-\mathrm{HT}$. 

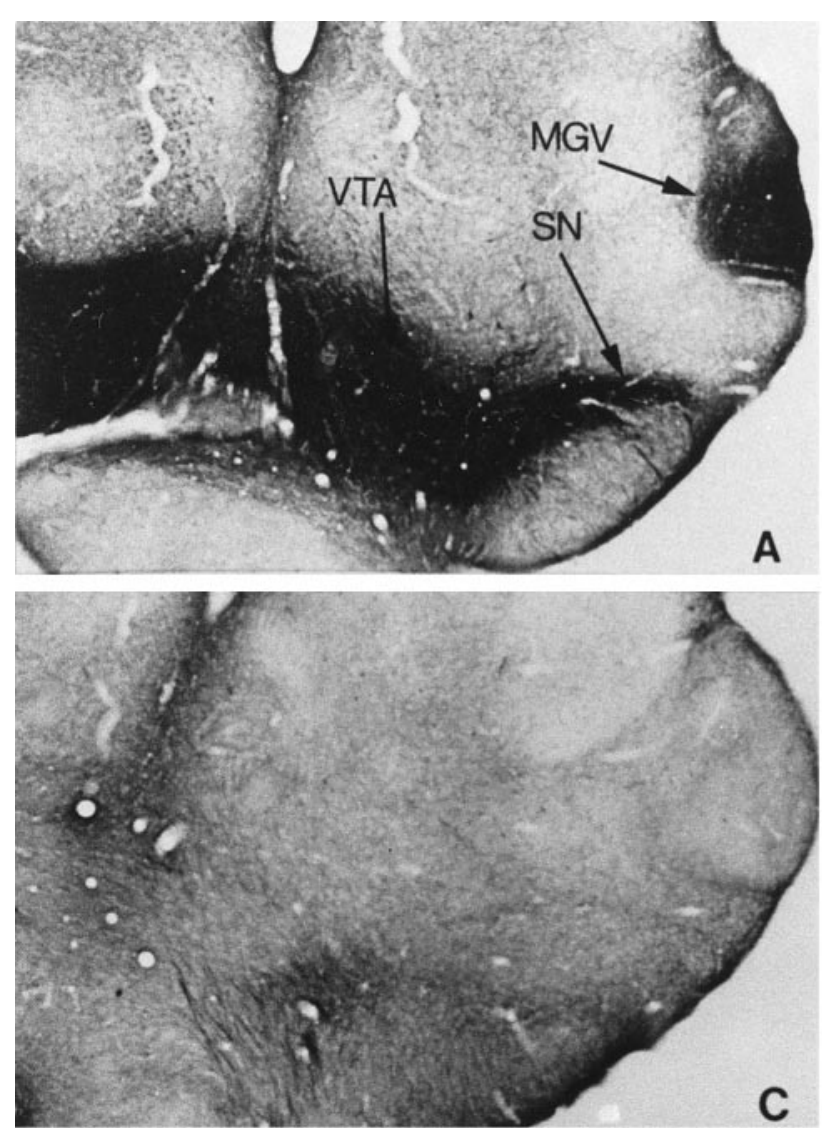

4

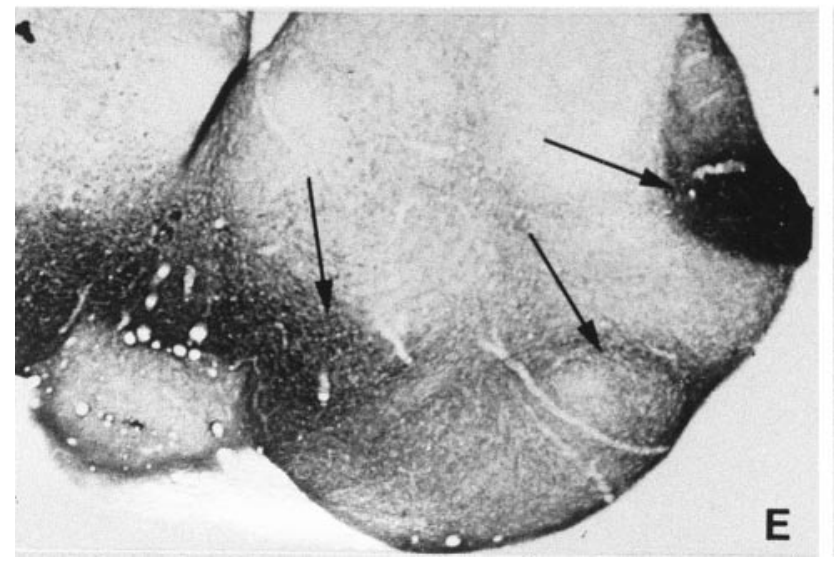

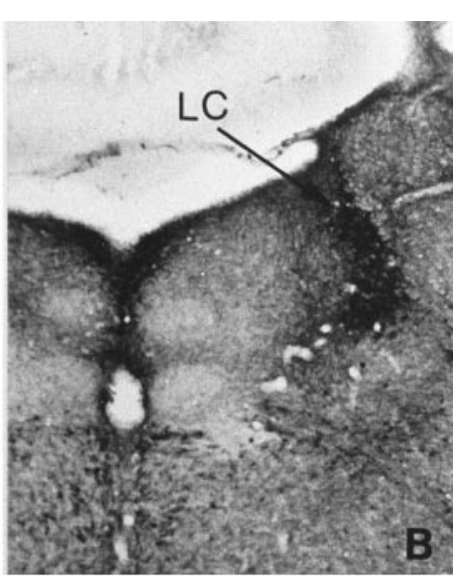
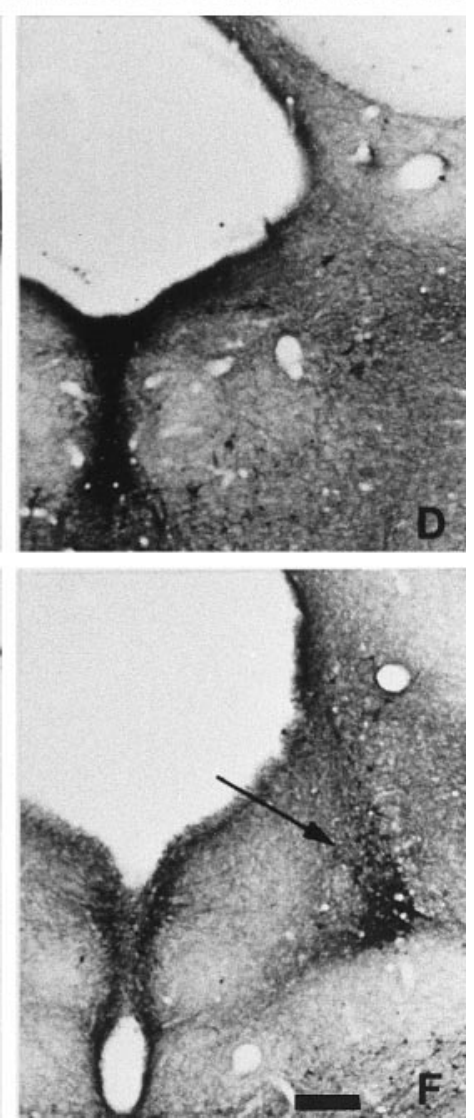

Figure 8. Lack of 5-HT accumulation in dopaminergic cell bodies of P7 MAOADAT double knock-outs. Comparable coronal brain sections are shown in the metencephalon $(A, C, E)$ and the pons $(B$, $D, F)$ of mice knock-outs for MAOA ( $A$, $B)$, DAT $(C, D)$, or both MAOA and DAT $(E, F) . A, B$, In the MAOA single knock-out, 5-HT-containing neurons are observed in the MGV, SN, VTA, and LC. $C, D$, In contrast, in the DAT single knock-out, no 5-HT-containing neurons are observed in the MGV, SN, VTA, and LC. $E, F$, In the MAOA-DAT double knock-out, 5-HT-containing neurons are still observed in the MGV and LC but are no longer observed in the SN and VTA. Scale bar: $A-F, 265 \mu \mathrm{m}$.
Changes in the orbital cortex would be interesting to investigate in adult MAOA knock-outs, which display altered sexual, aggressive, and nociceptive behaviors (Cases et al., 1995; Kim et al., 1997). The orbital cortex is implicated in complex olfactory behaviors, such as olfactory-guided male sexual behavior (Eichenbaum et al., 1980; Sapolsky and Eichenbaum, 1980; Slotnick and Kaneko, 1981) and intermale aggression (De Bruin et al., 1983; De Bruin, 1990; Kolb and Gibb, 1990). In addition to causing developmental defects possibly leading to behavioral alterations in adult MAOA knock-outs, the considerable levels of 5-HT in the brain of MAOA knock-outs during the first 2 postnatal weeks have been shown to acutely cause much exaggerated behavioral responses. For example, P12 pups display defensive biting and prolonged responses to tail pinches. These behaviors may involve the orbital cortex and the SUB.

Abnormal segregation of neuronal projections in MAOA knock-outs is not confined to cortical fields and has been observed in the lower brain. In a preliminary report, we indicated that the segregation of contralateral and ipsilateral retinal projections is abnormal in the dorsal lateral geniculate thalamus of MAOA knock-outs (Upton et al., 1997; A. L. Upton, N. Salichon, I. Seif, and P. Gaspar, personal communication). This suggests that the projections from the LSO, which is involved in binaural hearing, could also be altered (Shneiderman and Henkel, 1987; Rietzel and Friauf, 1998). LSO neurons receive glutamatergic excitatory and glycinergic inhibitory neurons originating from the ipsilateral and contralateral ear, respectively, along an exquisitely organized tonotopic gradient (Caird and Klinke, 1983). During perinatal development, there is a shift in the effects of glycinergic inputs received by LSO neurons that have depolarizing effects before P8 and hyperpolarizing effects thereafter (Kandler and Friauf, 1995). LSO projects to the central nucleus of the inferior 
colliculus. Most of the ipsilateral projection is glycinergic and most of the contralateral projection is glutamatergic, although this remains controversial (Glendenning et al., 1992; Moore et al., 1995; Saint Marie, 1996), and there appears to be little overlap of the ipsilateral and contralateral terminals (Shneiderman and Henkel, 1987). In MAOA knock-outs, 5-HT-positive neuronal cell bodies were observed in the lateral and central LSO (a region that responds to lower sound frequencies). Immunocytochemical and tracing experiments are needed to establish the nature of these 5-HT-containing neurons (glycinergic or glutamatergic) and the degree of patterning of their projections.

In the anterior cingulate cortex, a part of the brain involved in attention, 5-HT immunolabeling was located in pyramidal-like neurons of the deep layers of the cortical plate. The topography and morphology of these 5-HT-accumulating neurons resemble that of the pioneering callosal neurons that have been described in the rat cingulate cortex (Koester and O'Leary, 1994). In rabbits, prenatal exposure to cocaine, a general inhibitor of monoamine uptake systems, alters the bundling of apical dendrites of anterior cingulate pyramidal cells (Levitt et al., 1997), and in male rats, prenatal exposure reduces the midsagittal area of the corpus callosum (Ojima et al., 1996). It could be speculated that 5-HT has an effect on the differentiation and growth of these cortical neurons and that cocaine acts in part by elevating extracellular levels of 5-HT.

In conclusion, our study points to particular neurons that could develop abnormal projections in children exposed to drugs enhancing brain levels of 5-HT or in individuals having a genetic deficiency in MAOA (Brunner et al., 1993; Lenders et al., 1998) or SERT. This study also emphasizes how mice that have been genetically modified, here with a null mutation of the MAOA gene, could be a most valuable model to exacerbate and visualize unexpected mechanisms.

\section{REFERENCES}

Amara SG, Kuhar MJ (1993) Neurotransmitter transporters: recent progress. Annu Rev Neurosci 16:73-93.

Arai R, Karasawa N, Nagatsu T, Nagatsu I (1995) Exogenous L-hydroxytryptophan is decarboxylated in neurons of the substantia nigra pars compacta and locus coeruleus of the rat. Brain Res 669:145-149.

Beaudet A, Descarries L (1979) Radioautographic characterization of a serotonin-containing nerve cell group in the adult rat hypothalamus. Brain Res 160:231-243.

Bennett-Clarke CA, Leslie MJ, Chiaia NL, Rhoades RW (1993) Serotonin $1 \mathrm{~B}$ receptors in the developing somatosensory and visual cortices are located on thalamocortical axons. Proc Natl Acad Sci USA 90:153-157.

Berger B, Glowinski J (1978) Dopamine uptake in serotoninergic terminals in vitro: a valuable tool for the histochemical differentiation of catecholaminergic and serotoninergic terminals in rat cerebral structures. Brain Res 147:29-45.

Blakely RD, Berson HE, Fremeau RT, Caron MG, Peek MM, Prince HK, Bradley CC (1991) Cloning and expression of a functional serotonin transporter from rat brain. Nature 354:66-70.

Bruning G, Liangos O, Baumgarten HG (1997) Prenatal development of the serotonin transporter in mouse brain. Cell Tissue Res 289:211-221.

Brunner HG, Nelen M, Breakefield XO, Ropers HH, Van Oost BA (1993) Abnormal behavior associated with a point mutation in the structural gene for monoamine oxidase A. Science 262:578-580.

Caird DM, Klinke R (1983) Processing of binaural stimuli by cat superior olivary complex neurons. Exp Brain Res 52:385-399.

Cases O, Seif I, Grimsby J, Gaspar P, Chen K, Pournin S, Muller U, Aguet M, Babinet C, Shih JC, De Maeyer E (1995) Aggressive behavior and altered amounts of brain serotonin and norepinephrine in mice lacking MAOA. Science 268:1763-1766.

Cases O, Vitalis T, Seif I, De Maeyer E, Sotelo C, Gaspar P (1996) Lack of barrels in the somatosensory cortex of monoamine oxidase
A-deficient mice: role of serotonin excess during the critical period. Neuron 16:297-307.

Chan-Palay V (1977) Indoleamine neurons and their processes in the normal rat brain and in chronic diet-induced thiamine deficiency ]demonstrated by uptake of ${ }^{3} \mathrm{H}$-serotonin. J Comp Neurol 176:467-493.

Ciliax BJ, Heilman C, Demchyshyn LL, Pristupa ZB, Ince E, Hersch SM, Niznik HM, Levey AL (1995) The dopamine transporter: immunochemical characterization and localization in brain. J Neurosci 15:1714-1723.

Consolazione A, Milstein C, Wright B, Cuello AC (1981) Immunocytochemical detection of serotonin with monoclonal antibodies. J Histochem Cytochem 29:1425-1430.

Coulter CL, Happe HK, Murrin LC (1996) Postnatal development of the dopamine transporter: a quantitative autoradiographic study. Dev Brain Res 92:172-181.

D'Amato R, Blue ME, Largent BL, Lynch DR, Ledbetter DJ, Molliver ME, Snyder SH (1987) Ontogeny of the serotonergic projection to rat neocortex: transient expression of a dense innervation of primary sensory areas. Proc Natl Acad Sci USA 84:4322-4326.

De Bruin JPC (1990) Social behaviour and the prefrontal cortex. Prog Brain Res 85:485-497.

De Bruin JPC, Van Oyen HGM, Van De Poll N (1983) Behavioural changes following lesions of the orbital prefrontal cortex in male rats. Behav Brain Res 10:209-232.

Doucet G, Descarries L, Audet MA, Garcia S, Berger B (1988) Radioautographic method for quantifying regional monoamine innervations in the rat brain. Application to the cerebral cortex. Brain Res 441:233-259.

Eichenbaum H, Shedlack KJ, Eckmann KW (1980) Thalamocortical mechanisms in odor-guided behavior. I. Effects of lesions of the mediodorsal thalamic nucleus and frontal cortex and olfactory discrimination in the rat. Brain Behav Evol 17:255-275.

Fontaine B, Changeux JP (1989) Localization of nicotinic acetylcholine receptor $\alpha$-subunit transcripts during myogenesis and motor endplate development in the chick. J Cell Biol 108:1025-1037.

Franklin KBJ, Paxinos G (1994) The mouse brain in stereotaxic coordinates. San Diego: Academic.

Fujimiya M, Kimura H, Maeda T (1986) Postnatal development of serotonin nerve fibers in the somatosensory cortex of mice studied by immunochemistry. J Comp Neurol 246:191-201.

Giros B, Caron MG (1993) Molecular characterization of the dopamine transporter. Trends Pharmacol Sci 14:43-49.

Giros B, El Mestikawy S, Bertrand L, Caron MG (1991) Cloning and functional characterization of a cocaine-sensitive dopamine transporter. FEBS Lett 295:149-154.

Giros B, Jaber M, Jones SR, Wightman RM, Caron MG (1996) Hyperlocomotion and indifference to cocaine and amphetamine in mice lacking the dopamine transporter. Nature 379:606-612.

Glendenning KK, Baker BN, Hutson KA, Masterton RB (1992) Acoustic chiasm V: inhibition and excitation in the ipsilateral and contralateral projections of LSO. J Comp Neurol 319:100-122.

Groenewegen HJ, Berendse HW, Wolters JG, Lohman AHM (1990) The anatomical relationship of the prefrontal cortex with the striatopallidal system, the thalamus and the amygdala: evidence for a parallel organization. Prog Brain Res 85:95-118.

Gu Q, Singer W (1995) Involvement of serotonin in developmental plasticity of kitten visual cortex. Eur J Neurosci 7:1146-1153.

Hansson SR, Mezey E, Hoffman BJ (1998) Serotonin transporter messenger RNA in the developing rat brain: early expression in serotonergic neurons and transient expression in non-serotonergic neurons. Neuroscience 83:1185-1201.

Helton RA, Harrison WA, Kelley K, Kane MA (1993) Melatonin interactions with cultured murine B16 melanoma cells. Melanoma Res 3:403-413.

Jaeger CB, Ruggiero DA, Albert VR, Joh TH, Reis DJ (1984) Immunocytochemical localization of aromatic-L-amino acid decarboxylase. In: Handbook of chemical neuroanatomy, Vol 2, Classical transmitters in the CNS, Pt I (Bjorklund A, Hokfelt T, eds), pp 387-408. Amsterdam: Elsevier.

Joh TH, Ross ME (1983) Preparation of catecholamine synthesizing enzymes as immunogen for immune histochemistry. In: Immunochemistry, IBRO Handbook series, Vol 3 (Cuello AC, ed), pp 121-151. Chichester, England: Wiley.

Kandler K, Friauf E (1995) Development of glycinergic and glutamater- 
gic synaptic transmission in the auditory brainstem of perinatal rats. J Neurosci 15:6890-6904.

Kim JJ, Shih JC, Chen K, Chen L, Bao S, Maren S, Anagnostaras SG, Fanselow MS, De Maeyer E, Seif I, Thompson RF (1997) Selective enhancement of emotional, but not motor, learning in monoamine oxidase A-deficient mice. Proc Natl Acad Sci USA 94:5929-5933.

Koester SE, O'Leary DDM (1994) Axons of early generated neurons in cingulate cortex pioneer the corpus callosum. J Neurosci 14:6608-6620.

Kolb B, Gibb R (1990) Anatomical correlates of behavioural change after neonatal prefrontal lesions in rats. Prog Brain Res 85:241-256.

Ladvas AA, Blue ME, Lincoln J, Parnavelas JG (1997) Serotonin promotes the differentiation of glutamate neurons in organotypic slice cultures of the developing cerebral cortex. J Neurosci 17:7872-7880.

Lebrand C, Cases O, Aldebrecht A, Doye A, Alvarez C, El Mestikawy S, Seif I, Gaspar P (1996) Transient uptake and storage of serotonin in developing thalamic neurons. Neuron 17:823-835.

Lebrand C, Cases D, Wehrle R, Blakely RD, Edwards RH, Gaspar P (1998) Transient developmental expression of monoamine transporters in the rodent forebrain. J Comp Neurol, in press.

Lenders JW, Brunner HG, Murphy DL, Eisenhofer G (1998) Genetic deficiencies of monoamine oxidase enzymes: a key to understanding the function of the enzyme in humans. Adv Pharmacol 42:297-301.

Levitt P, Harvey JA, Friedman E, Simansky K, Murphy EH (1997) New evidence for neurotransmitter influences on brain development. Trends Neurosci 20:269-274.

Lichtensteiger W, Mutzner U, Langemann H (1967) Uptake of 5-hydroxytryptamine and 5-hydroxytryptophan by neurons of the central nervous system normally containing catecholamines. J Neurochem 14:489-497.

Lidov HGW, Molliver ME (1982a) An immunohistochemical study of serotonin neuron development in the rat: ascending pathways and terminal fields. Brain Res Bull 8:389-430.

Lidov HGW, Molliver ME (1982b) Immunohistochemical study of the development of serotonergic neurons in the rat CNS. Brain Res Bull 9:559-604.

Liu C, Weaver DR, Jin X, Shearman LP, Pieschl RL, Gribkoff VK, Reppert SM (1997) Molecular dissection of two distinct actions of melatonin on the suprachiasmatic circadian clock. Neuron 19:91-102.

Moiseiwitsch JR, Lauder JM (1995) Serotonin regulates mouse cranial neural crest migration. Proc Natl Acad Sci USA 92:7182-7186.

Moore DR, Russel FA, Cathcart NC (1995) Lateral superior olive projections to the inferior colluculus in normal and unilaterally deafened ferrets. J Comp Neurol 357:204-216.

Nelson N, Lill H (1994) Porters and neurotransmitter transporters. J Exp Biol 196:213-228.

Nirenberg MJ, Chan J, Vaughan RA, Uhl GR, Kuhar MJ, Pickel VM (1997) Immunogold localization of the dopamine transporter: an ultrastructural study of the rat tegmental area. J Neurosci 17:5255-5262.

Ojima K, Abiru H, Fukui Y (1996) Effects of cocaine on the rat cerebral commissure. Int J Dev Neurosci 14:649-654.

Pacholczyk T, Blakely RD, Amara SG (1991) Expression cloning of a cocaine- and antidepressant-sensitive human noradrenaline transporter. Nature 350:350-354.

Paxinos G, Tork I, Tecott LH, Valentino KL (1991) Atlas of the developing rat brain. San Diego: Academic.

Price JL, Slotnick BM (1983) Dual olfactory representation in the rat thalamus: an anatomical and electrophysiological study. J Comp Neurol 215:63-77.

Rhoades RW, Bennett-Clarke CA, Chiaia NL, White FA, McDonald GJ, Haring JH, Jacquin MF (1990) Development and lesion induced reorganization of the cortical representation of the rat's body surface as revealed by immunochemistry for serotonin. J Comp Neurol 293:190-207.
Rhoades RW, Bennett-Clarke CA, Shi MY, Mooney RD (1994) Effects of 5-HT on thalamocortical synaptic transmission in the developing rat. J Neurophysiol 72:2438-2450.

Rietzel H-J, Friauf E (1998) Neuron types in the rat superior olive and developmental changes in the complexity of their dendritic arbors. J Comp Neurol 390:20-40.

Roberts VJ, Dong WK (1994) The effect of thalamic nucleus submedius lesions on nociceptive responding in rats. Pain 57:341-349.

Saint Marie RL (1996) Glutamatergic connections of the auditory midbrain: selective uptake and axonal transport of $\mathrm{D}-\left({ }^{3} \mathrm{H}\right)$ aspartate. J Comp Neurol 373:255-270.

Sapolsky RM, Eichenbaum H (1980) Thalamocortical mechanisms in odor-guided behavior. II. Effects of lesions of the mediodorsal thalamic nucleus and frontal cortex on odor preferences and sexual behavior in the hamster. Brain Behav Evol 17:276-290.

Schambra UB, Lauder JM, Silver J (1992) Atlas of the prenatal mouse brain. San Diego: Academic.

Shaskan EG, Snyder SH (1970) Kinetics of serotonin accumulation into slices from rat brain: relationship to catacholamine uptake. J Phar Exp Ther 175:404-418.

Shneiderman A, Henkel CK (1987) Banding of lateral superior olivary nucleus afferents in the inferior colliculus: a possible substrate for sensory integration. J Comp Neurol 266:519-534.

Slotnik BM, Kaneko N (1981) Role of the mediodorsal thalamic nucleus in olfactory discrimination learning in rats. Science 214:91-92.

Steinbusch HWM (1981) Distribution of serotonin-immunoreactivity in the central nervous system of the rat-cell bodies and terminals. Neuroscience 6:557-618.

Steinbusch HWM, Verhofstad AAJ, Joosten HWJ, Golstein M (1982) Serotonin-immunoreactive cell bodies in the nucleus dorsomedialis hypothalami, in the substantia nigra, and in the area tegmentalis ventralis of Tsai: observations after pharmacological manipulations in the rat. In: Cytochemical methods in neuroanatomy, pp 407-421. New York: Liss.

Upton AL, Lebrand C, Salichon N, Ezan P, Seif I, Gaspar P (1997) Serotonin uptake in retinal ganglion cells during development of normal and MAOA-knockout mice. Soc Neurosci Abstr 23:639.

van den Pol AN (1986) Gamma-aminobutyrate, gastrin releasing peptide, serotonin, somatostatin, and vasopressin: ultrastructural immunocytochemical localization in presynaptic axons in the suprachiasmatic nucleus. Neuroscience 17:643-659.

van den Pol AN, Tsujimoto KL (1985) Neurotransmitters of the hypothalamic suprachiasmatic nucleus: immunocytochemical analysis of 25 neuronal antigens. Neuroscience 15:1049-1086.

Vanhatalo S, Soinila S (1994) Pharmacological characterization of serotonin synthesis and uptake suggest a false neurotransmitter role for serotonin in the pituitary intermediate lobe. Neurosci Res 21:143-149.

Vitalis T, Cases O, Callebert J, Launay JM, Price DJ, Seif I, Gaspar P (1998) Effects of monoamine oxidase A inhibition on barrel formation in the mouse somatosensory cortex. Determination of a sensitive developmental period. J Comp Neurol 393:169-184.

Wallace JA, Lauder JM (1983) Development of the serotonergic system in rat embryo: an immunocytochemical study. Brain Res Bull 10:459-479.

Yoshida A, Dostrovsky JO, Sessle BJ, Chiang CY (1991) Trigeminal projections to the nucleus submedius of the thalamus in the rat. J Comp Neurol 307:609-625.

Yoshida A, Dostrovsky JO, Chiang CY (1992) The afferent and efferent connections of the nucleus submedius in the rat. J Comp Neurol 324:115-133. 